\title{
Muscarinic Induction of Synchronous Population Activity in the Entorhinal Cortex
}

\author{
Clayton T. Dickson and Angel Alonso \\ Department of Neurology and Neurosurgery, Montreal Neurological Institute and McGill University, Montreal, Quebec, \\ Canada H3A 2B4
}

\begin{abstract}
Oscillation and synchronization of neural activity is important in normal brain function but is also relevant to epileptogenesis. One of the most frequent forms of epilepsy originates in temporal lobe circuitry of which the entorhinal cortex $(E C)$ is crucial. Because muscarinic receptor activation promotes oscillatory dynamics in EC neurons, we investigated in a brain slice preparation the effects of carbachol (CCh) on oscillatory population activity in the EC. We found that CCh produced epileptiform activity in EC, which according to field profile and current source density analysis was usually driven by layer V. In addition, localized CCh application and surgical isolation experiments demonstrated that EC layer II, but not layer III, can also independently generate synchronous population activity.

Intracellular recordings from EC principal cells during epileptiform activity demonstrated large-amplitude, synaptically driven depolarizing events and bursts of action potentials synchronized to the field spikes. In layer II neurons, the depolariz-
\end{abstract}

ing events had a multiphasic reversal potential that suggested concurrent glutamatergic and GABAergic synaptic input. Interestingly, although the epileptiform activity required activation of AMPA but not NMDA receptors, small-amplitude field spikes persisted during block of fast excitatory neurotransmission. These field spikes were correlated to large-amplitude IPSPS in layer II neurons, and both activities were abolished by $\mathrm{GABA}_{\mathrm{A}^{-}}$ receptor antagonism. Thus, in response to muscarinic activation, pools of EC interneurons discharge synchronously by a mechanism not necessarily involving principal cell activation.

Given the differential projection pattern of EC layers V and II toward the neocortex and hippocampus, respectively, their robust epileptogenic character may be of major importance in temporal lobe epilepsy.

Key words: temporal lobe epilepsy; parahippocampal gyrus; cholinergic; oscillation; pacemaker; inhibition
The majority of intractable epilepsy cases involve foci located in the mesial aspect of the temporal lobes (Lothman et al., 1991). To understand the basic mechanisms of temporal lobe epilepsy and to suggest more efficacious pharmacological and/or surgical treatments (Engel, 1987), it is important to define a precise locus for the generation of ictal activity in the temporal lobe. In general, most research approaches concerning this disorder have focused on the contribution of the hippocampal formation (Lothman et al., 1991; Schwartzkroin, 1994). Recent experimental and clinical studies, however, have suggested that the entorhinal cortex (EC) may play a similar or more important role in temporal lobe epilepsy (Dasheiff and McNarmara, 1982; Walther et al., 1986; Wilson et al., 1988; Rutecki et al., 1989; Deutch et al., 1991; Goldring et al., 1992; Jones et al., 1992; Paré et al., 1992; Stringer and Lothman, 1992; Spencer and Spencer, 1994; Bragin et al., 1997).

The EC is known to be a "gateway" for the bi-directional passage of information in the neocortical-hippocampalneocortical circuit (Van Hoesen, 1982; Witter et al., 1989; Lopes da Silva et al., 1990). Via a cascade of cortico-cortical projections, the superficial layers of the EC (II and III) receive an extensive input from polymodal sensory cortices (Jones and Powell, 1970;

Received April 16, 1997; revised June 4, 1997; accepted June 10, 1997.

This work was supported by a grant from the Canadian Medical Research Council. Dr. Dickson was supported by a fellowship from the Natural Sciences and Engineering Council of Canada. Dr. Alonso is a Montreal Neurological Institute Killam Scholar

Correspondence should be addressed to Dr. A. Alonso, Department of Neurology and Neurosurgery, Montreal Neurological Institute and McGill University, Montreal, Quebec, Canada H3A 2B4.

Copyright (C) 1997 Society for Neuroscience $0270-6474 / 97 / 176729-16 \$ 05.00 / 0$
Van Hoesen and Pandya, 1975; Amaral et al., 1983; Deacon et al., 1983; Room and Groenewegen, 1986; Insausti et al., 1987; Reep et al., 1987) that is then conveyed to the hippocampal formation via the perforant path (Steward and Scoville, 1976). In turn, the hippocampal formation projects back on the deep layers of the EC (V-VI) (Swanson and Cowan, 1977), which provide output paths that reciprocate the input channels (Swanson and Kohler, 1986; Insausti et al., 1997). In addition, the deep layers of the EC also project massively on the EC superficial layers (Kohler, 1986b; Dolorfo and Amaral, 1997), thereby closing an EC-hippocampal loop. Thus, by virtue of its extensive projection systems, the EC network may act powerfully in the generalization of temporal lobe seizures.

The EC is also known to receive a prof use cholinergic input from the basal forebrain that terminates primarily in layers II and V (Lewis and Shute, 1967; Mellgren and Srebro, 1973; Milner et al., 1983; Alonso and Köhler, 1984; Lysakowski et al., 1989; Gaykema et al., 1990), precisely those layers that gate the main hippocampal input and output. It is well known that the cholinergic system promotes cortical activation and the expression of normal population oscillatory dynamics. In the EC, in vivo electrophysiological studies have shown that the cholinergic theta rhythm is generated primarily by cells in layer II (Mitchell and Ranck, 1980; Alonso and García-Austt, 1987a,b; Dickson et al., 1995). In addition, in vitro studies have also shown that muscarinic receptor activation promotes the development of intrinsic oscillations in EC layer II neurons (Klink and Alonso, 1997a,b).

On the other hand, some evidence indicates that altered activity of the cholinergic system is relevant to epileptogenesis. Phar- 
macological activation of cholinergic receptors may promote and maintain epileptiform discharge (for review, see Turski et al., 1989), and cholinergic neurotransmission seems necessary for the normal progression of kindling (Cain, 1989). Upregulation in the levels and activity of both acetylcholine and its metabolic enzymes has also been reported in human epilepsy (Pope et al., 1947; Tower and McEarchern, 1949; Tower and Elliot, 1952; Coutinho-Netto et al., 1981; Kish et al., 1988). In the EC, expression of muscarinic receptor protein is increased in kindlinginduced epileptic animals (Beldhuis et al., 1993), and the EC also shows a lower threshold for carbachol (CCh)-induced electrographic seizure activity than the hippocampus (Dickson, 1994).

Given the above information, and that $\mathrm{CCh}$ is known to induce rhythmic population activity in the hippocampus in vitro (Konopacki et al., 1987; MacVicar and Tse, 1989; Traub et al., 1992; Huerta and Lisman, 1993; Bianchi and Wong, 1994), we considered it important to test whether moderate muscarinic receptor activation would also trigger oscillatory population activity in the EC slice and to explore the relation of this activity to an epileptogenic state. Our study demonstrates that $\mathrm{CCh}$ induces, in the EC slice, large-amplitude rhythmic field activity correlated to the development of paroxysmal depolarizations in all EC principal neurons. We further demonstrate that muscarinicinduced epileptiform activity can be generated independently by both superficial (layer II) and deep laminae (layers V-VI). Moreover, CCh was found to synchronize not only principal cells but also inhibitory interneurons, and this even in the absence of fast excitatory neurotransmission (Michelson and Wong, 1994).

Some of these data have been published previously in abstract form (Dickson and Alonso, 1995a,b; Klink et al., 1995).

\section{MATERIALS AND METHODS}

General. Brain slices were prepared from male Long-Evans rats (100$250 \mathrm{gm}$ ) using standard procedures (Alonso and Klink, 1993). Animals were decapitated, and the brain was rapidly removed, blocked, and placed in a cold $\left(4-6^{\circ} \mathrm{C}\right)$ oxygenated Ringer's solution containing (in mM): $124 \mathrm{NaCl}, 5 \mathrm{KCl}, 1.2 \mathrm{NaH}_{2} \mathrm{PO}_{4}, 2.4 \mathrm{CaCl}_{2}, 1.3-2.6 \mathrm{MgSO}_{4}, 26$ $\mathrm{NaHCO}_{3}$, and 10 glucose, $\mathrm{pH} 7.4$, by saturation with $95 \% \mathrm{O}_{2} / 5 \% \mathrm{CO}_{2}$. Horizontal slices from the retrohippocampal region were cut at a thickness of $400 \mu \mathrm{m}$ using a Vibratome (Pelco, Redding, CA) and typically did not include the hippocampal formation, because our focus was on oscillatory mechanisms within the EC. After at least a $1 \mathrm{hr}$ recovery period during which they were submerged at room temperature, individual slices were transferred to an interface chamber maintained at $34 \pm 1^{\circ}$ and superfused at a rate of $1-2 \mathrm{ml} / \mathrm{min}$. The borders and the cellular layers of the EC were discerned with a dissecting microscope and a transilluminatory light source.

Drugs were mixed fresh weekly and stored and refrigerated in stock solutions at 100 - to 1000 -fold concentrations. They were mixed to their final concentrations in graduated cylinders filled with Ringer's solution that were attached to the superfusion tubing. Carbamylcholine $(\mathrm{CCh})$, atropine sulfate, bicuculline methiodide, and picrotoxin (PTX) were purchased from Sigma (St. Louis, MO), and 6-cyano-7-nitroxaline-2,3dione (CNQX), and DL(-)-2-amino-5-phosphonopentanoic acid (AP-5) were purchased from Tocris Cookson (Langford, UK). Salts used in the making of Ringer's solution were all purchased from BDH (Toronto, Ontario, Canada).

Recording and stimulation. Recording electrodes were pulled from micropipette glass (World Precision Instruments, Sarasota, FL) on a Sutter Instruments puller (Novato, CA). Extracellular field electrodes were filled with Ringer's solution (tip resistance 5-10 M $\Omega$ ), and intracellular electrodes were filled with $2.5 \mathrm{M}$ potassium acetate (tip resistance $60-120 \mathrm{M} \Omega$ ).

Field and intracellular signals were amplified using both channels of an Axoclamp 2A amplifier (Axon Instruments, Foster City, CA). Field signals were further amplified by a CyberAmp amplifier (Axon Instruments) to a final gain of 1000 and filtered at a bandpass of $0.1-1.0 \mathrm{kHz}$ (some signals were recorded with the DC component and later filtered).
Signals were visualized on-line using two digital storage oscilloscopes at slow and fast screen sweep speeds, and stored on VHS tape (NeuroCorder, New York, NY) for off-line analysis using a 386-based computer.

Bipolar stimulation electrodes were constructed from two strips of fine tungsten wire glued along their length and insulated except at their tips. The two poles were positioned straddling the angular bundle obliquely (tip separation $\sim 300 \mu \mathrm{m}$ ) above the medial portion of the EC. Electrical stimulation was delivered using a square wave generator (MNI technical services) coupled to a constant current/stimulus isolation unit (World Precision Instruments), and stimuli consisted of $1 \mathrm{msec}$ square waves of amplitude 2-5 V. Field potentials effects of stimulation were measured in layer II.

Field and intracellular activities were digitized from tape at sampling rates ranging from 1 to $50 \mathrm{kHz}$ and plotted using a software acquisition package (Acqui, SICMU, Geneva, Switzerland). The amplitude of field spikes was calculated as the difference from peak to trough of the field waveform. Duration of field spikes was measured from the onset of negativity to the crossing point at the same potential level. In addition, field activity filtered at a bandpass of $1-40 \mathrm{~Hz}$ and sampled at $1 \mathrm{kHz}$ was subjected to Fast Fourier Transform using a software package (Origin, Microcal Software, Northampton, MA) for analysis in the frequency domain. The predominant frequency of the signal was taken from the fundamental peak of the resulting spectra.

Field profiles. A stationary (reference) electrode was positioned in layer $\mathrm{V}$ while a roving electrode was moved along a plane orthogonal to the laminations of the EC in $50 \mu \mathrm{m}$ stepwise increments. The reference and roving electrodes were separated in the medial axis by $<50 \mu \mathrm{m}$, and care was taken to ensure that the trajectory of the roving electrode remained in the same column along the depth of the profile. Up to 16 field events were sampled at each level, and typically 10 events were averaged for each using the reference waveform for temporal alignment. The averaged field potential values were then stored in two-dimensional (space vs time) matrices and plotted as a three-dimensional contour plot (Origin).

Current source density (CSD) analysis (Mitzdorf, 1985) was conducted by direct computation of the second spatial derivative of the extracellular voltage potentials. Briefly, the potential values corresponding to all spatial depths at each time point were fitted with a seventh order polynomial. The second derivative of this function was then computed. Derivative functions for each time point were then stored in matrix form and plotted in the same fashion as for the extracellular potentials.

Horizontal field profiles were constructed in much the same manner as laminar profiles. A stationary (reference) electrode was positioned in either layer II or V, and the roving electrode was moved in $50-100 \mu \mathrm{m}$ stepwise increments along the same medial-to-lateral axis within the confines of the same cellular layer. When averaging was conducted, traces were averaged as described above.

Laminar CCh application profiles. Laminar localized application of $\mathrm{CCh}$ was conducted during simultaneous field recordings made in both layers II and $\mathrm{V}$ by fast $(10-50 \mathrm{msec})$ pressure pulses (Picospritzer, General Valve, Fairfield, NJ) to the back of a patch pipette containing 10 $\mathrm{mm} \mathrm{CCh}$ in a $1 \%$ solution of Luxol Fast Blue in Ringer's solution. The dye was added to visualize the area of the slice inundated to ensure that the area of application was highly localized and lamina specific. Only those applications that were confined to the lamina of interest were subsequently analyzed. In some experiments, $1 \mu \mathrm{M}$ atropine sulfate was added to the superfusing Ringer's solution during the applications to ensure that the recorded field effects were specific to the muscarinic actions of CCh.

Laminar isolation experiments. Cellular layers were separated physically by scalpel cuts that were made in a clear petri dish filled with oxygenated Ringer's solution after the removal of the slice from the recording chamber. Slices were quickly replaced in the chamber after successful completion of the cuts and reperfused with $\mathrm{CCh}$. In some cases, a broken pipette was used to separate cellular layers without removal from the recording chamber. In additional experiments, the isolation cuts were made before incubation with $\mathrm{CCh}$.

Intracellular recordings. Intracellular impalements were made in layers II, III, and V. Only neurons fulfilling the following criteria were reported in the following study: resting membrane potential negative to $-55 \mathrm{mV}$, input resistance $>30 \mathrm{M} \Omega$, and overshooting spikes of amplitude $>60 \mathrm{mV}$. Superficial EC neurons were identified electrophysiologically according to criteria outlined previously (Alonso and Klink, 1993; Dickson et al., 1997). Briefly, layer II stellate cells (SCs) showed profound timedependent inward rectification in the hyperpolarizing direction and 


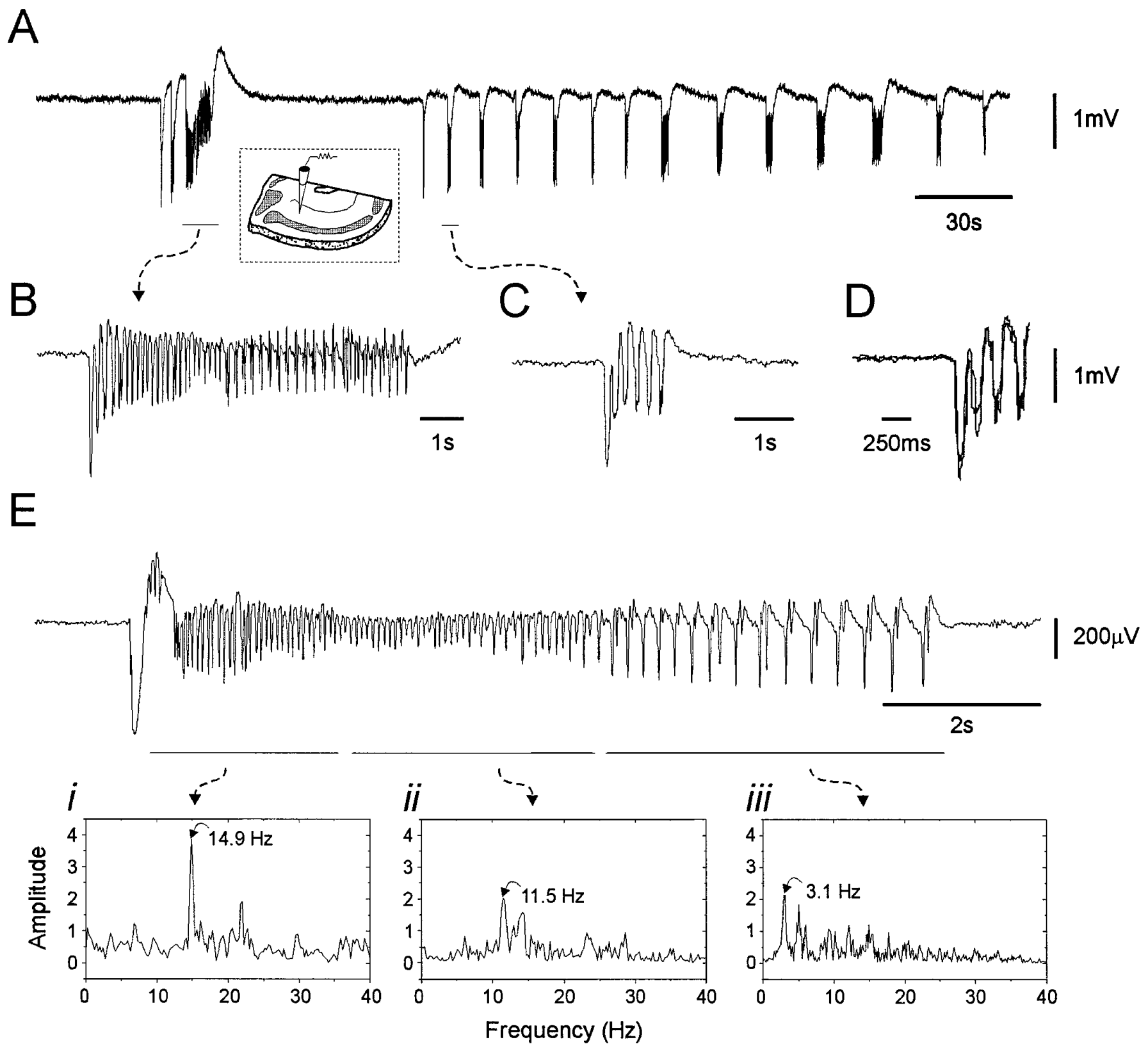

Figure 1. Population (field) activity elicited in entorhinal slices perfused with CCh $(20 \mu \mathrm{M})$. A, After 6 min of perfusion with CCh, large-amplitude rhythmic field events typically develop. The inset demonstrates the experimental setup. $B$, An AC recording of the initial LDE in $A$ at an expanded time scale. $C$, An AC recording of an SDE in $A$ shown at an expanded time scale. $D$, A superimposition of the first five field spikes in $B$ and $C$. Note the very good correspondence between the two. E, An AC recording of an LDE elicited in another experiment. Multiple phases can be seen corresponding to the lines underneath the analog recording. Fast Fourier Transforms corresponding to the three phases are shown below, with the fundamental peak frequency noted. In this and in all subsequent figures, negativity is down.

prominent subthreshold membrane potential oscillations and cluster spiking on DC depolarization. Layer II pyramidal-like cells showed less robust time-dependent inward rectification with hyperpolarizing pulses and no rhythmic subthreshold oscillations. In addition to their location in distinctly observable lamina, layer III pyramids showed high input resistance $(<70 \mathrm{M} \Omega)$ and no, or only minor, time-dependent inward rectification with hyperpolarizing current pulses, and went easily into tonic firing with DC depolarization (Dickson et al., 1997).

\section{RESULTS}

\section{General characteristics of $\mathrm{CCh}$-induced population activity}

Bath application of moderate concentrations of CCh $(10-30 \mu \mathrm{M})$ induced rhythmic large-amplitude $(>500 \mu \mathrm{V})$ field activity in
$55 \%$ (67 of 122) of EC slices tested without previous control for field responses to angular bundle stimulation. The success rate of rhythmic population activity induction was much higher (20 of 21; 95\%), however, when CCh was applied to EC slices selected for responding to angular bundle electrical stimulation, with an evoked field potential in layer II of at least $500 \mu \mathrm{V}$.

The induction and maintenance of rhythmic field activity by $\mathrm{CCh}$ was dependent on muscarinic receptor activation because it was blocked by atropine (300 nM-1 $\mu \mathrm{M} ; n=9)$. As illustrated in Figure 1, the CCh-induced field activity had an epileptiform morphology. It was typically initiated by a long-duration ictiform event (LDE: 5-40 sec in duration) (Fig. $1 A, B$ ) and was usually 
Table 1. Summary of features of long-duration ictiform events

\begin{tabular}{|c|c|c|c|c|c|c|c|c|c|c|c|c|c|}
\hline \multirow[b]{2}{*}{ Duration(s) } & \multicolumn{5}{|c|}{ Frequency $(\mathrm{Hz})$} & \multicolumn{4}{|c|}{ Field spike duration (msec) } & \multicolumn{4}{|c|}{ Field spike amplitude $(\mu \mathrm{V})$} \\
\hline & InterLDE & IntraLDE & Tonic & Trans & Clonic & Overall & Tonic & Trans & Clonic & Overall & Tonic & Trans & Clonic \\
\hline $10.6 \pm 7.4$ & $0.010 \pm 0.006$ & $7.9 \pm 4.1$ & $14.4 \pm 4.5$ & $7.5 \pm 3.3$ & $4.0 \pm 1.0$ & $162 \pm 121$ & $108 \pm 53$ & $128 \pm 65$ & $226 \pm 157$ & $446 \pm 267$ & $450 \pm 319$ & $463 \pm 270$ & $432 \pm 233$ \\
\hline
\end{tabular}

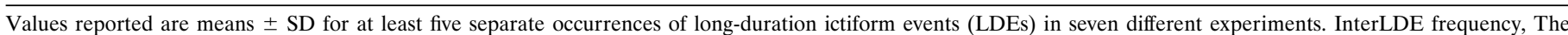

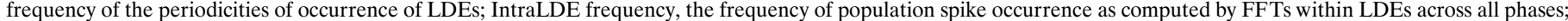

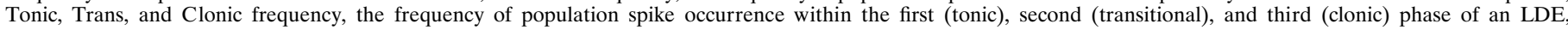

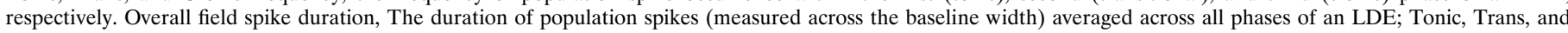

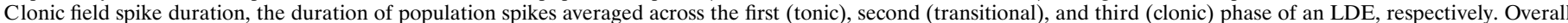

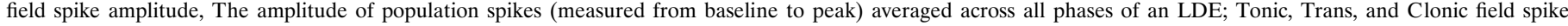
amplitude, the amplitude of population spikes averaged across the first (tonic), second (transitional), and third (clonic) phase of an LDE, respectively.

Table 2. Summary of features of short-duration ictiform events

\begin{tabular}{|c|c|c|c|c|}
\hline \multirow[b]{2}{*}{ Duration(s) } & \multicolumn{2}{|c|}{ Frequency $(\mathrm{Hz})$} & \multicolumn{2}{|c|}{ Field spike } \\
\hline & InterSDE & IntraSDE & $\begin{array}{l}\text { Duration } \\
(\mathrm{msec})\end{array}$ & $\begin{array}{l}\text { Amplitude } \\
(\mu \mathrm{V})\end{array}$ \\
\hline $1.06 \pm 0.85$ & $0.30 \pm 0.31$ & $7.7 \pm 5.0$ & $147 \pm 50$ & $767 \pm 438$ \\
\hline
\end{tabular}

Values reported are means \pm SD for nine different experiments. InterSDE frequency, The frequency of the periodicities of occurrence of short-duration ictiform events (SDEs); IntraSDE frequency, the frequency of population spike occurrence within SDEs; field spike duration and amplitude, the duration (across baseline) and amplitude (baseline to peak) of population spikes within an SDE.

followed by a slow periodic occurrence of short-duration ictiform events (SDEs: $0.1-4,0 \mathrm{sec}$ in duration) (Fig. $1 \mathrm{~A}, \mathrm{C}$ ). Occasionally, however, LDEs would show a similar periodicity, although at slower frequencies $(<0.05 \mathrm{~Hz})$ (see Figs. 6, 9). Aside from their differences in duration and interevent frequency, both LDEs and SDEs were similar in their initial waveform pattern (Fig. $1 D$ ).

As recorded in layer $\mathrm{V}$, LDEs consisted of a train of negativegoing population spikes superimposed on a large-amplitude $(0.5-$ $1.4 \mathrm{mV}$ ) negative DC potential (Fig. $1 A$ ). As in the cases illustrated in Figure $1 B, E$, LDEs were consistently multiphasic, having at least two and sometimes three phases of population spike activity with different spectral peak frequencies, which resembled the tonic and clonic phases characteristic of an electrographic seizure with a "transition" phase occasionally interposed between. The features of LDEs are summarized in Table 1 . Essentially, the tonic phase was characterized by a train of high frequency population spikes $(14.4 \mathrm{~Hz})$, whereas the transitional and clonic phases showed progressively slower frequencies of field spikes (7.5 and $4.0 \mathrm{~Hz}$, respectively) (Fig. $1 E$ ). Similarly, the duration of individual population spikes tended to increase as the event progressed. The average amplitude of population spikes, however, was relatively constant over the three phases when summed over all cases but could show systematic variations in individual cases, such as the increase-decrease-increase sequence shown in Figure $1 E$.

SDEs consisted of large-amplitude negative-going field potentials typically associated with a repetitive sequence of field spikes (Fig. $1 A, C$ ), often resembling those seen during the LDEs (Fig. $1 D)$. In fact, the average frequency of these field spikes $(7.7 \mathrm{~Hz})$ (Table 2) was virtually identical to the average population spike frequency summed over all phases of the LDEs $(7.9 \mathrm{~Hz})$ (Table 1). SDEs typically repeated with a clock-like rhythmicity (Fig. $1 A$ ) at a frequency that ranged from 0.05 to $0.6 \mathrm{~Hz}$ for different cases. The quantified features of SDEs are summarized in Table 2.

\section{Field profile and CSD analysis}

In an attempt to clarify which EC layer acts as the generator of $\mathrm{CCh}$-induced epileptiform activity, we examined the laminar dis- tribution of field events to construct laminar field potential profiles and perform CSD analysis for the localization of the main sinks and sources of current $(n=6)$. A typical case is illustrated in Figure 2. As shown in Figure $2 A$, a stationary electrode (red) was positioned in layer $\mathrm{V}$ while a moving electrode (blue) was advanced in $50 \mu \mathrm{m}$ steps from the pial surface (layer I) to the angular bundle in a direction normal to the cortical layers. Figure $2 B$ illustrates the laminar field potential profile corresponding to the initial $60 \mathrm{msec}$ of averaged SDEs recorded at distinct locations (indicated to the left). The corresponding reference recordings used to construct the profile have been superimposed at the top (red). It can be observed that a robust field negativity (corresponding to a population spike) appeared first in layers V-VI and then successively at later times in layer III and then in layer II. Using the latency values corresponding to the peak negativities in the respective lamina, the speed of propagation was calculated to be $110 \pm 14 \mathrm{~mm} / \mathrm{sec}$. Although appearing first in layers V-VI, the field negativity in layer III showed both a greater amplitude and longer duration. The laminar field profile in Figure $2 B$ has been represented as a contour plot in the right panel of Figure $2 C$. Field negativity has been coded in the hot (red) end of the spectrum and was initiated in the deep layers and propagated superficially to layer III and finally to layer II.

The left panel of Figure $2 C$ represents the contour plot for the CSD analysis of the field potential profile in $B$ and $C$. Current sinks have been coded in the hot (red) end of the spectrum. Note that a distinct short-lasting (2-3 msec) current sink appeared first in layers V-VI. A second but much larger current sink developed next in layer III, where it extended over the full extent of the layer progressing from its deepest border with layer IV (lamina dessicans) to the transition with layer II, where it stopped. A third distinct and final current sink then developed in layer II. The sequential development of current sinks first in layers V-VI, then in layer III, and finally in layer II suggests that these epileptiform discharges are typically generated in the deep layers of EC and then propagated actively toward layers III and II after the known ascending pathways (Kohler, 1986a). As is the case in the CSD profile of Figure 2, it was a consistent observation that in layer $\mathrm{V}$ the initial current sink was always followed by two other sinks at a fixed interval of $\sim 5 \mathrm{msec}$, thus indicating that the population activity in layer $\mathrm{V}$ occurred as a high frequency $(\sim 200 \mathrm{~Hz})$ population oscillation. In contrast, in layer III the initial shortlasting current sink was followed at $\sim 5 \mathrm{msec}$ by a second, maintained sink of very long duration $(\sim 20 \mathrm{msec})$. On the other hand, in layer II, only the initial short-lasting current sink was typically observed.

We also wanted to examine whether the activity generated in layers V-VI occurred synchronously over the full horizontal extent of the layer or whether there was some specific focal zone 
A

B
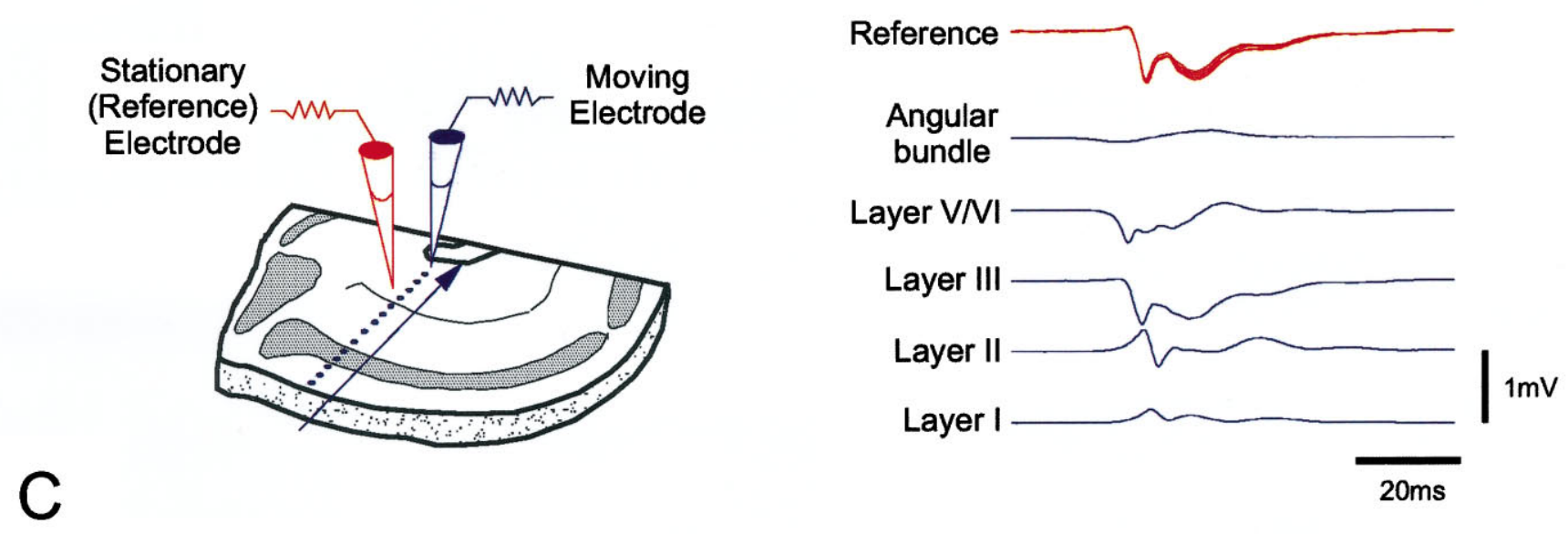

Field Profile
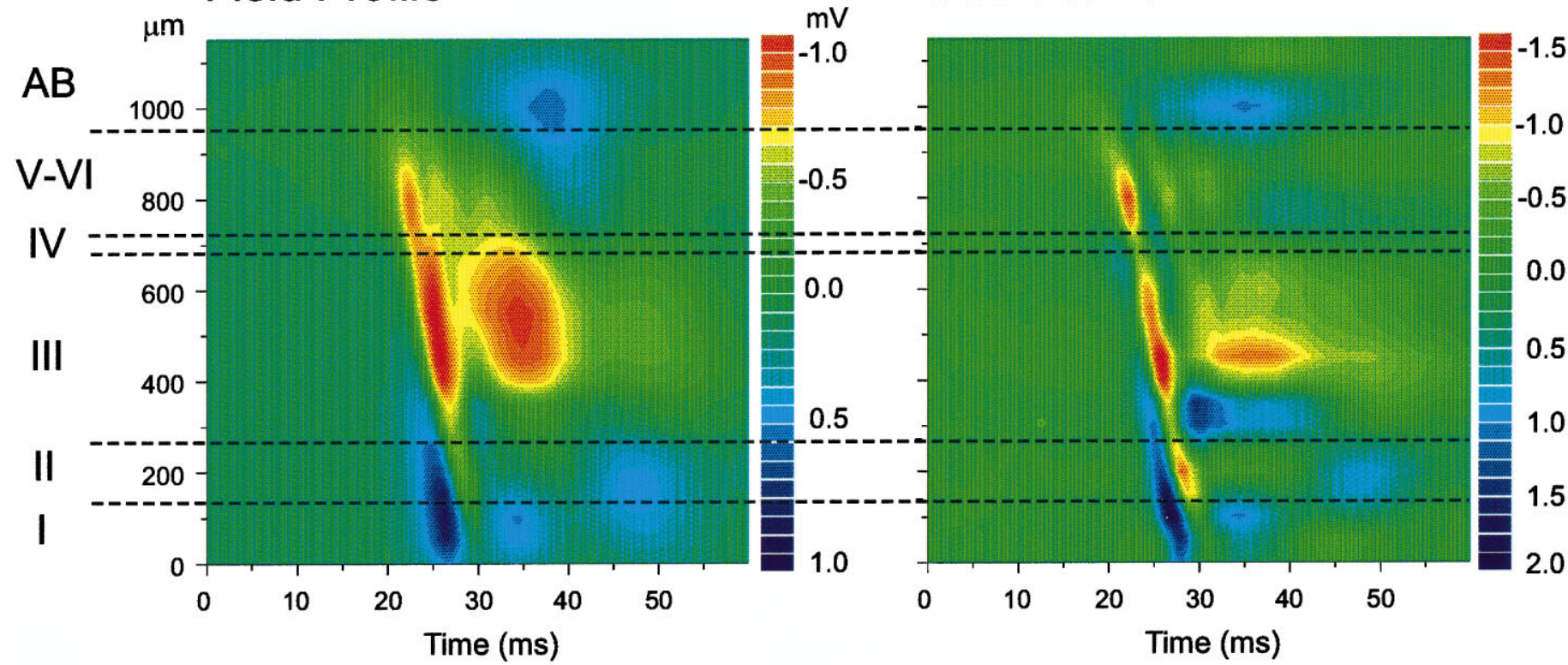

Figure 2. Laminar field potential profile and CSD analysis of epileptiform events. A, A representation of the experimental scheme. A stationary (reference) electrode was located in layers V-VI while another electrode (moving) was advanced from the pial surface (layer I) to the deep layers [angular bundle $(A B)$ ] in $50 \mu \mathrm{m}$ increments. $B$, Field potential profile of the first $60 \mathrm{msec}$ of an SDE recorded at the layers noted. The superimposed traces at the top represent the field potentials recorded at the level of the reference electrode at all levels shown and were used to align the traces recorded from the moving electrode. The latency from the onset of the peak negativity in layers V-VI to layers III and II was 3.0 and 5.9 msec, respectively. $C$, Pseudocolor surface contour plot of the field potential (left panel) and CSD (right panel) profile. The field negativity is observed first in layers V-VI from where it propagates to layers III and II. It is largest and shows the longest duration in layer III. Associated with the initial field negativities are spatially distinct current sinks lasting for $\sim 2 \mathrm{msec}$, seen first in layers V-VI and subsequently in layers III and II. After the initial sink there is a rhythmic reappearance of sinks in layers V-VI (approximate frequency $200 \mathrm{~Hz}$ ), whereas a more tonic sink of elongated duration (12 msec) appears in layer III, far outlasting those in either layers V-VI or II.

from which the activity was propagated. With this in mind we constructed field potential profiles along the mediolateral axis of layer $\mathrm{V}$ (horizontal profiles, $n=6$ ). A typical experiment is illustrated in Figure 3. The diagram in Figure $3 A$ summarizes the experimental protocol. The reference electrode was positioned in the most medial portion of layer $\mathrm{V}$, and a moving electrode was advanced at fixed steps $(100 \mu \mathrm{m})$ along layer V. Representative recordings of SDEs recorded at increasing distances from the reference electrode are plotted in Figure $3 B$. The top traces in this panel are a superimposition of all averaged reference recordings during the track. Note that SDEs recorded at increasing lateral distances from the reference recording occur at increasing latencies, thus indicating that in this case the epileptiform activity propagated in the mediolateral direction along layer $\mathrm{V}$ at a speed of $\sim 100 \mathrm{~mm} / \mathrm{sec}$ (Fig. 3D, open circles). Occasionally (such as the case illustrated in Fig. 3), SDEs could appear at the same recording site with two different waveforms (Fig. $3 C$ ). Although the events corresponding to one of the waveforms showed positive latencies at increasing lateral distances from the reference $(B, C$, $D$; open circles), the other showed negative latencies $(C, D$; filled circles) that indicated independent focal events showing opposing propagation directions in the mediolateral axis. Although independent, the speed of propagation of epileptiform activity in either the mediolateral (open circles) or lateromedial direction 
A

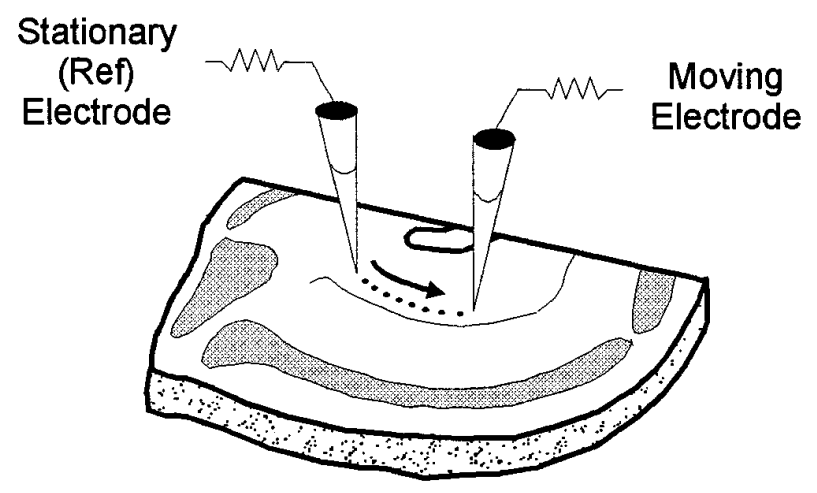

C
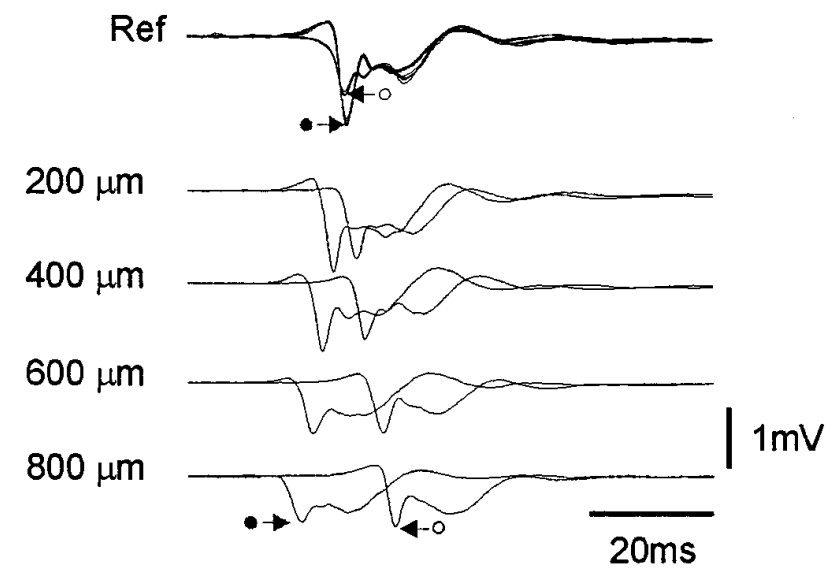

B

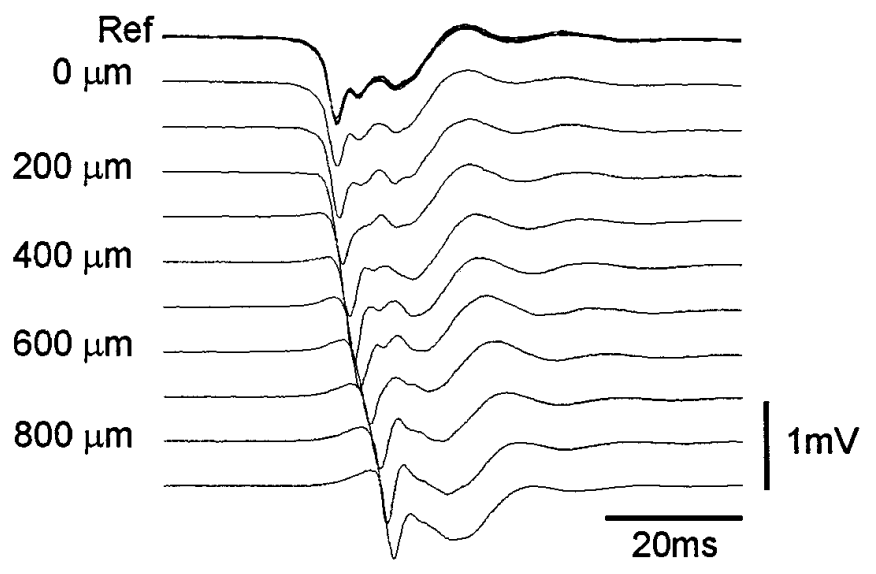

D

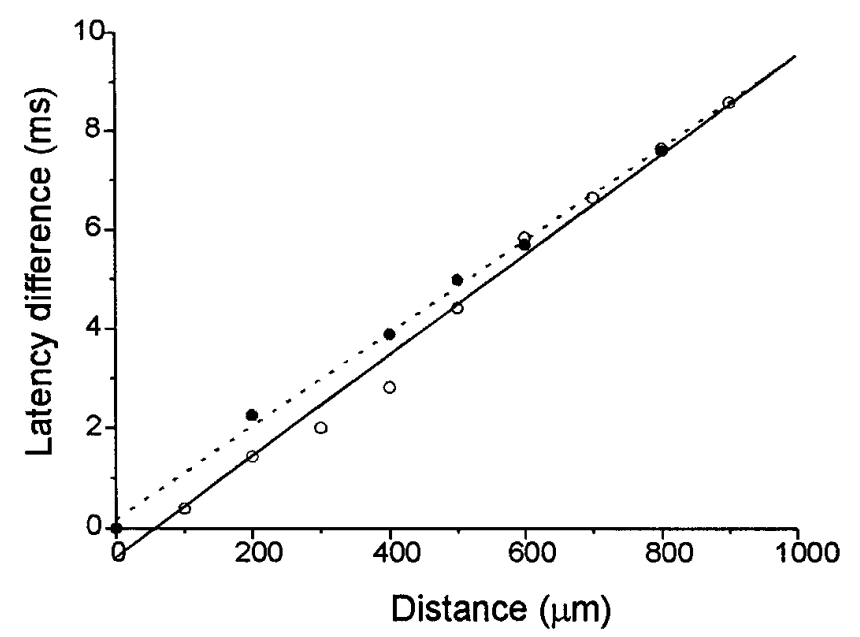

Figure 3. Horizontal propagation of epileptiform events in the entorhinal slice. $A$, Representation of the experimental protocol. A reference electrode was placed in the medial aspect of layers V-VI while a moving electrode was advanced in $100 \mu \mathrm{m}$ increments along the medial-lateral axis of layers V-V I. $B$, Horizontal profile of the first $60 \mathrm{msec}$ of an SDE. The traces at the top represent the superimposition of the potentials recorded at the reference electrode site for each of the horizontal levels shown below. As the moving electrode was moved further in a lateral direction the latency difference increased, indicating a medial to lateral propagation of the event. $C$, Combined horizontal profile for two distinct SDEs as distinguished by their different waveforms as recorded at the level of the stationary reference electrode $(A)$. The events alternated in their occurrence and appeared to propagate in opposite directions. One event is the same as in $B(\bigcirc)$ and propagated in the medial-to-lateral direction as indicated by the increasing latency from the reference at increasing recording distances. The second $(\bullet)$ propagated in the lateral-to-medial direction as suggested by the opposite temporal relation. $D$, A regression plot of the relationship between the latency differences between the activity at the stationary and the moving electrode for both SDEs shown in $C$. Both events appear to travel at similar speeds across the horizontal aspect of the slice. The average propagation speed of the event shown in $B(\bigcirc)$ was $111 \mathrm{~mm} / \mathrm{sec}$, whereas the second event shown in $C(\bullet)$ propagated at $100 \mathrm{~mm} / \mathrm{sec}$.

(filled circles) was almost identical $(D)$. These results suggest the existence of multiple focal generators of epileptiform activity within layer $\mathrm{V}$ that can be propagated in either the lateral or medial direction in the horizontal axis of the slice.

\section{Surgical isolations and pressure pulse application}

Although the above data indicate that layers V-VI play a leading role in the generation of epileptiform activity in the EC, our laboratory has shown that $\mathrm{CCh}$ has a robust facilitatory action on the intrinsic oscillatory and bursting properties of EC layer II neurons (Klink and Alonso, 1997a,b). Also, projection neurons from layer II display a prof use net of recurrent collaterals that are likely to excite neighboring cells (R. Klink and A. Alonso, un- published observations). Thus, the electrophysiology and anatomy of EC layer II suggests that this layer could act as an independent pacemaker for oscillatory dynamics. Indeed, in those cases $(n=10)$ in which we monitored the induction of epileptiform activity using $\mathrm{CCh}$ by making dual simultaneous recordings in both layer II and layer V, low-amplitude short-duration field events were observed occasionally $(n=2)$ in layer II before any field activity in layer $\mathrm{V}$.

To examine the issue of whether EC layer II could independently generate synchronous population activity, we initially performed focal $\mathrm{CCh}$ applications in layers II, III, and V while we simultaneously recorded field activity in layers II and V (Fig. 4A) 
A

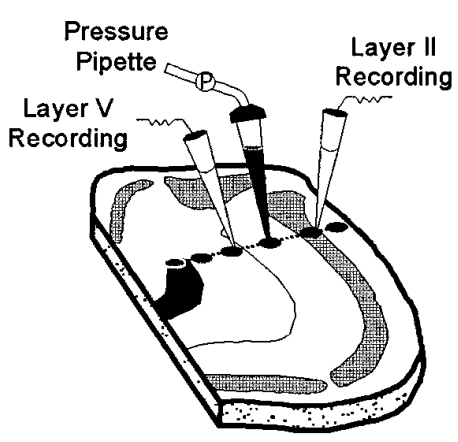

B Layer II application
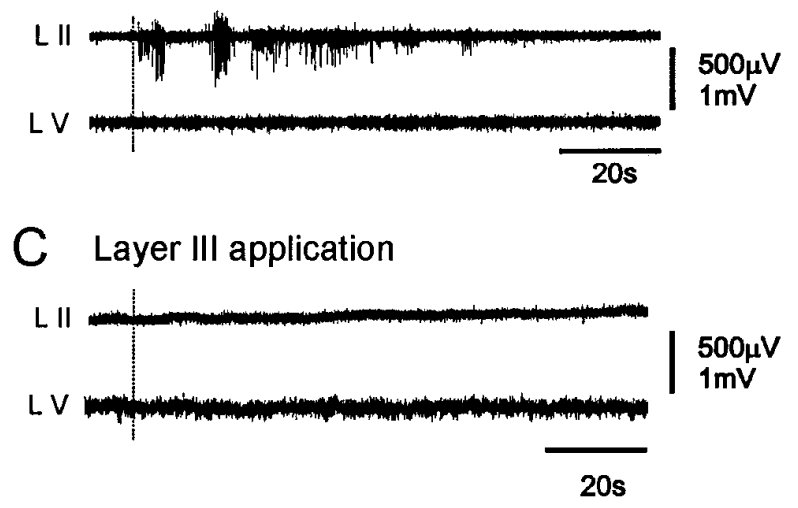

D Layer IV-V application

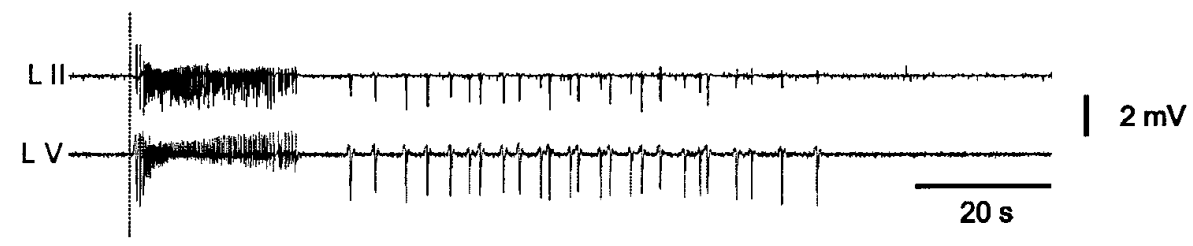

E Layer VI-AB application

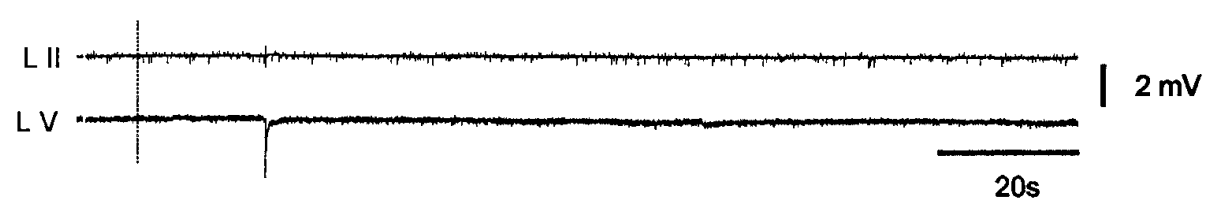

Figure 4. Field effects of laminarlocalized pressure pulse applications of CCh (10 mM) in the entorhinal slice. $A$, A diagrammatic representation of the recording and application arrangement. Two stationary recording electrodes were located in layers II and V. A pressure pipette was placed consecutively in layers I, II, III, V, and VI and in the angular bundle $(A B)$, and a $10 \mathrm{msec}$ pulse was administered at each point. $B$, Layer II application (denoted by the vertical line). After only a short delay, small-amplitude epileptiform activity was recorded in layer II. Note the absence of activity in layer V. $C$, Layer III application. No activity was elicited. $D$, Layer V application. A long-lasting series of large-amplitude epileptiform events of both long and short duration were elicited in layer $\mathrm{V}$ and propagated to layer II. These events are remarkably similar to those engendered by bath perfusion of CCh (see Fig. 1). E, Layer VI application. One short-duration field spike was elicited at a long delay from the onset of the pressure pulse. $(n=17)$. As illustrated in Figure $4 B$, in $30 \%$ of the cases $(n=$ $17)$, pressure pulse applications of CCh in layer II evoked synchronous population activity localized exclusively to layer II. On the other hand, when $\mathrm{CCh}$ was focally applied to layer $\mathrm{V}$, a prolonged series of epileptiform events was consistently recorded $(100 \% ; n=17)$ by both layer V and layer II electrodes (Fig. 4D). This activity mimicked the onset of epileptiform discharges seen with bath perfusion of $\mathrm{CCh}$ in that the first event triggered by CCh was an LDE and was followed by short ictiform discharges. Focal CCh applications to layer III never resulted in the elicitation of epileptiform events, whereas applications to deep layer $\mathrm{VI} /$ angular bundle typically resulted in no activity or the onset of a small number of SDEs at long delays (Fig. $4 E$ ). In all cases tested $(n=3)$, it was found that atropine blocked the activity elicited by focal $\mathrm{CCh}$ applications at both layer II and layer V sites (not shown). Thus, these results suggest that both EC layers II and $\mathrm{V}$, but not layer III, contain the appropriate neuronal and circuit machinery to independently generate synchronous population activity.

To further clarify whether EC layer II could independently generate rhythmic population activity, we undertook surgical isolation experiments. In the intact EC slice, we first induced epileptiform activity with $\mathrm{CCh}$ to be ensured of the viability of the slice, and then under continuous CCh superfusion we cut the slice to separate the internal and external principal laminae. As shown in Figure 5, preserved epileptiform activity resembling that seen previous to the cut could be observed in most cases, in both the piece of slice containing the deep layers V-VI (Fig. 5A) (90\%; $n=19)$ or the superficial layers I-III (Fig. $5 B)(32 \% ; n=19)$ laminae. In additional cases, with surgical cuts that selectively isolated layer II, epileptiform activity was maintained over this layer (Fig. 5C) (3 of 12 cases). In no case, however, was activity maintained in a piece of slice containing only layer III $(n=10)$. In addition, field potential profiles conducted after surgical isolation of the superficial principal lamina (layers I-III; $n=3$ ) indicated that the remaining field activity was generated by layer II only and volume conducted to the remaining layer III.

To further substantiate the above results, surgical cuts separating the deep and superficial laminae were also performed before perfusion with CCh was undertaken $(n=21)$. In most of these cases $(n=19)$, the piece of slice containing the deep laminae showed patterns of epileptiform activity similar to those of intact slices when perfused with $\mathrm{CCh}$. Also, in several cases $(n=6)$ $\mathrm{CCh}$ application to the piece of slice containing layer II induced epileptiform activity (not shown). The above surgical isolation experiments indicate that both layers V-VI and layer II can act as independent pacemakers of synchronous population activity.

\section{Intracellular correlates}

We also investigated the intracellular correlates of the CChinduced epileptiform activity, particularly in neurons from layer II $(n=47)$, because they have been the most extensively characterized electrophysiologically, but also in neurons from layers III $(n=12)$ and V $(n=9)$. During both LDEs and SDEs, principal cells in all layers fired bursts of action potentials synchronized with the local negative-going field spikes (Figs. 6, 7). As in the specific layer II cell illustrated in Figure 6, in neurons from all layers, membrane voltage manipulation always revealed that the field-associated bursts of action potentials were driven by depolarizing events of synaptic nature. It was also apparent that in 
Figure 5. Effect of knife cuts separating the external and internal principal lamina on the maintenance of $\mathrm{CCh}$-induced epileptiform activity. $A$, Maintenance of LDEs and SDEs in the internal principal lamina after surgical separation of the superficial principal lamina. Left, A diagrammatic representation of the experiment is shown. The recording both preand post-cut was at the level of layer $\mathrm{V}$ in the internal (deep) principal lamina. The level of the cut is shown by the dotted line. Middle, Activity elicited by $\mathrm{CCh}$ before the surgical removal of the superficial laminae. Both SDEs and LDEs are shown. Right, Activity maintained in the deep laminae after the cut. Again, both LDEs and SDEs can be seen with a similar pattern of expression. $B$, Maintenance of LDEs and SDEs in the external principal lamina after surgical separation of the deep principal lamina. Left, A representation of the experiment is shown. The recording both pre- and post-cut was at the level of layer II in the superficial principal lamina. The level of the cut is shown by the dotted line. Before (middle) and after (right) the removal of the deep laminae, both SDEs and LDEs can be observed. The frequency of expression of SDEs appeared to quicken after the cut, but the overall pattern appears similar. $C$, In another experiment, recording pre- and post-cut was performed in both layers II and V. Activity is coincident in both layers previous to but not after the cut.
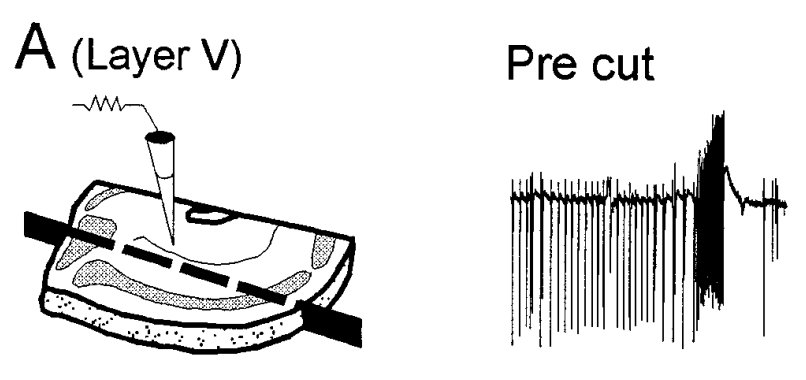

\section{Post cut}
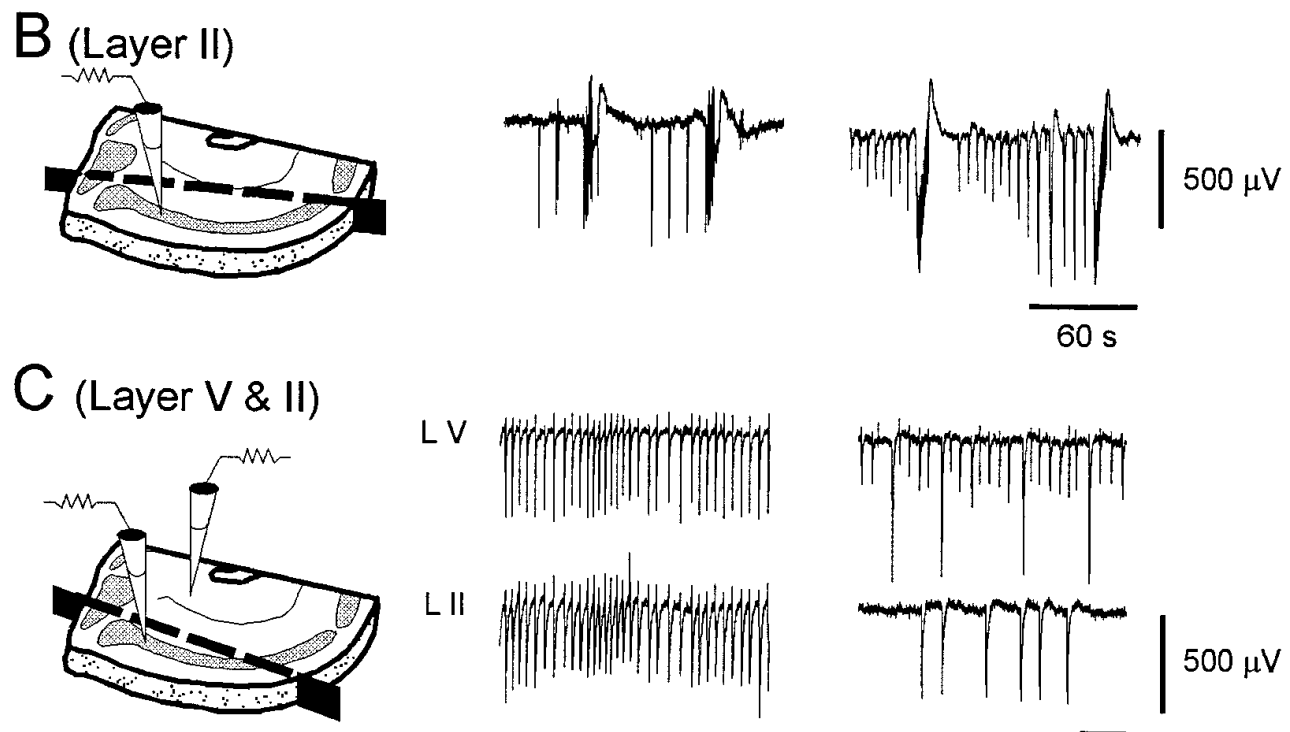

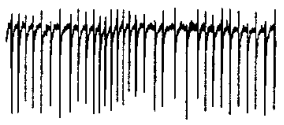

LII

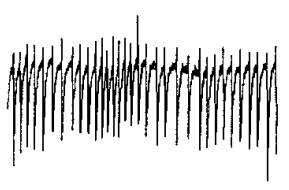

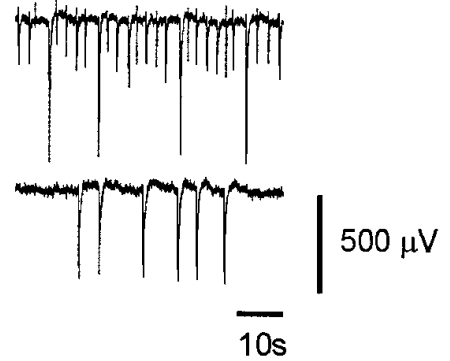

neurons from all layers the epileptiform discharges were typically associated with a plateau depolarization (Fig. 7; note dotted line in $A-D)$. This plateau depolarization was particularly prominent and considerably outlasted the field discharges in neurons from layers III and V in comparison to neurons from layer II (Fig. 7).

In layer II projections neurons, we explored the reversal potential of the synaptic events underlying the epileptiform discharges by means of DC current injection $(n=6)$. As in the case illustrated in Figure 8, the depolarizing synaptic events were always fully reversed at potentials positive to approximately $-40 \mathrm{mV}$; however, we could always detect at least two components that reversed at different potentials. There was an early phase that reversed at approximately $-50 \mathrm{mV}$ (Fig. $8 A$, arrow) and a later phase that reversed at membrane potentials $\sim 5-10 \mathrm{mV}$ more positive (Fig. 8A, asterisk) than the early phase. Among other factors, this multiphasic reversal potential may have resulted from the rather synchronous input onto projection cells of both glutamatergic- and GABAergic-mediated synaptic potentials. Consistent with this interpretation, three fast-spiking cells (presumably interneurons) that were briefly (1-3 $\mathrm{min}$ ) recorded during CCh-induced population activity also fired in bursts synchronized to the negative-going population spikes of the epileptiform events (not shown).

\section{Pharmacology}

Given the excitatory nature of the intracellular correlate of field epileptiform events, we sought to characterize their dependence on glutamatergic neurotransmission. Antagonism of NMDA receptor-mediated neurotransmission with AP-5 $(30 \mu \mathrm{M})$ did not abolish the epileptiform discharges in any of the cases tested $(n=$
6) (Fig. 9); however, it did produce some consistent effects. First, block of NMDA neurotransmission decreased the duration of individual population spikes from $179 \pm 40$ to $105 \pm 36 \mathrm{msec}$ and increased their frequency from $7.0 \pm 1.7$ to $14.2 \pm 4.1 \mathrm{~Hz}$. Second, NMDA receptor block also produced an increase in the duration of the epileptiform events from an average of $4.3 \pm 2.3$ to $6.1 \pm 1.5 \mathrm{sec}$ (Fig. 9).

The excitatory component of the field activity was dependent, however, on AMPA receptor-mediated glutamatergic transmission. It could be blocked by CNQX alone $(n=5)$ or in combination with AP-5 $(n=10)$ (Fig. 10). To our surprise, however, small-amplitude field activity always persisted in layer II after blockade of fast excitatory amino acid (EAA) neurotransmission (Fig. 10A,B). This activity was also present in surgically isolated layer II as well $(n=3)$, and typically consisted of positive-going field events (Figs. 10, 11). The intracellular correlate of this activity in layer II projection cells were large-amplitude IPSPs $(8 \pm 2 \mathrm{mV}$ at $61 \pm 2 \mathrm{mV} ; n=8)$ [for simplicity hereafter referred to as giant IPSPs (gIPSPs)] of a rather fast rate of rise $(43 \pm 21$ $\mathrm{msec}$ ) and slow decay (total duration, $903 \pm 116 \mathrm{msec}$ ) (Fig. $10 A-C)$. After peaking, these gIPSPs continuously decreased toward the resting level (Fig. 10B,C); however, we could typically distinguish, particularly at hyperpolarized levels, a decrease in the rate of decay at $\sim 100 \mathrm{msec}$ from the gIPSP onset (Fig. 10C). Membrane hyperpolarization revealed that gIPSP peak reversed at approximately $-75 \mathrm{mV}$ and the late phase at $\sim 10 \mathrm{mV}$ more negative (Fig. 10C) $(n=3)$.

Interestingly, we observed that when the extracellular and intracellular electrodes were separated by distances greater than 


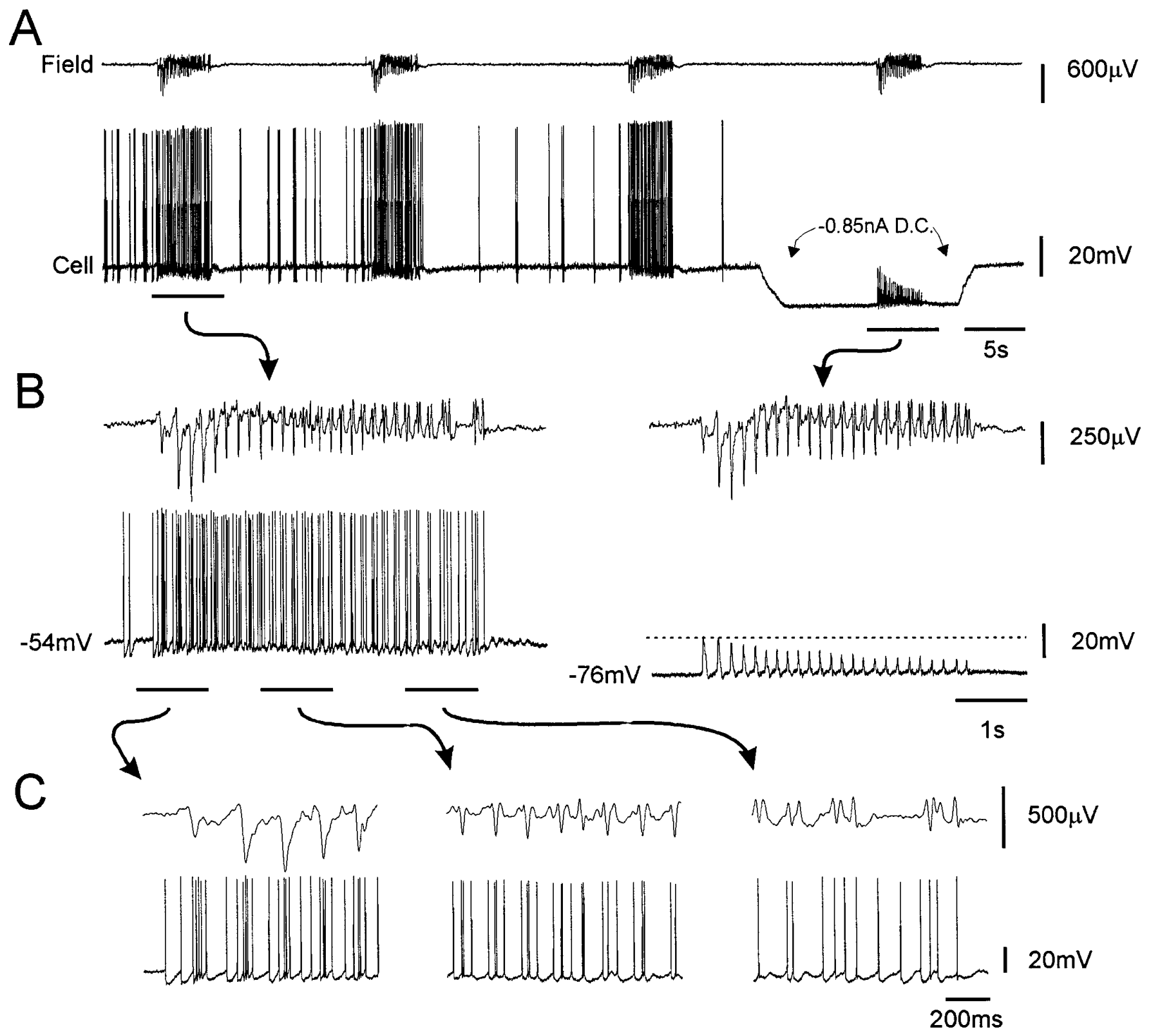

Figure 6. Activation of an electrophysiologically identified EC layer II SC during rhythmic epileptiform events evoked by CCh (20 $\mu \mathrm{M})$. The field recording location was in layer II, $150 \mu \mathrm{m}$ lateral to the intracellular electrode. $A$, Long trace showing the cell becoming strongly activated during epileptiform events. This cell was depolarized by $6 \mathrm{mV}$ in response to CCh before the initiation of field events. During the last field event shown, DC hyperpolarization unveiled large-amplitude depolarizing synaptic potentials synchronized with the negative field spikes. $B$, Fast sweep speed trace of the first and last epileptiform events shown in $A$. $C$, Higher sweep speed traces for the indicated periods of the epileptiform event shown in $B$.

$\sim 200 \mu \mathrm{m}$, there was a lack of synchrony between the field events and the intracellular gIPSPs. In addition, as in the case illustrated in Figure 10, even within this critical range there tended to be a lack of absolute consistency between the intracellular and extracellular recordings in terms of waveform and synchrony. To illustrate this point, all individual field events and gIPSPs from Figure $10 A$ have been superimposed in Figure $10 B$ at an expanded time scale. Note that gIPSPs could occur in the absence of a field event (Fig. 10A,B, asterisk), or conversely field events could occur in the absence of gIPSP (Fig. 10A, filled circle). In addition, the shape of the field waveform could occasionally vary, and although most gIPSPs were associated with a field event, they could occur at close but different time relations to the field event (Fig. 10B, right). Finally, we examined the effect of $\mathrm{GABA}_{\mathrm{A}}$ receptor antagonism with PTX $(100 \mu \mathrm{M})$ or bicuculline $(10 \mu \mathrm{M})$ on the field events and gIPSPs. As shown in Figure $10 D$, in all cases $(n=5) \mathrm{GABA}_{\mathrm{A}}$ receptor antagonism always abolished all field events and IPSPs that persisted during glutamatergic transmission block.

The above data suggest that gIPSPs may result from the synchronous firing of interneurons, the positive-going field events in layer II arising from the associated inhibitory currents in principal neurons. The lack of perfect synchrony between the gIPSPs and field events suggest, however, that there might be multiple pools of interneurons impinging on distinct (and perhaps overlapping) pools of principal cells. To further examine this possibility, we performed mediolateral and depth profiles of the layer II positive-going field events (Fig. $11 A-D)(n=5)$. Typically, a 


\section{A Layer II Stellate}

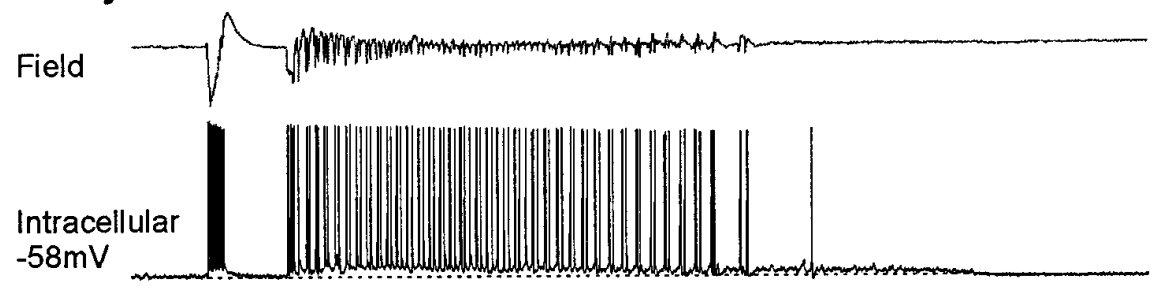

\section{B Layer II Non Stellate}

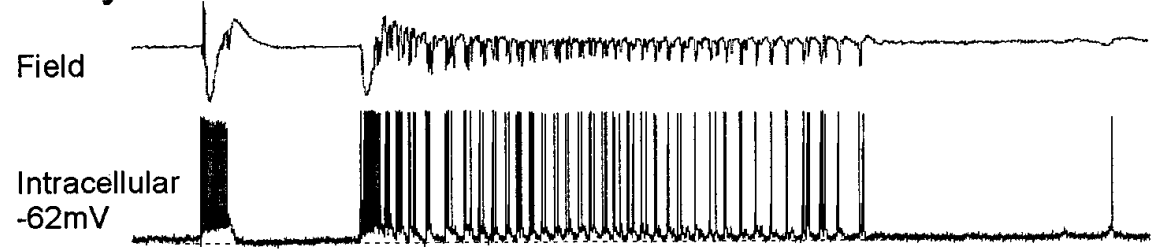

\section{Layer III Pyramid}

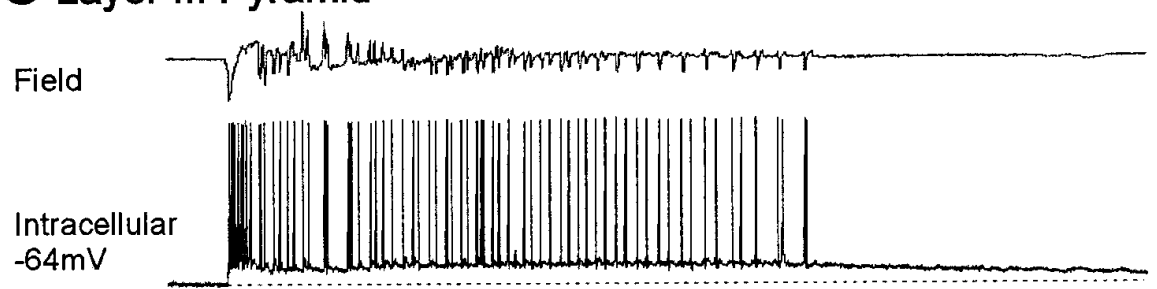

Figure 7. Typical recordings from entorhinal neurons during epileptiform events induced by $10 \mathrm{~mm}$ CCh. $A$, A layer II SC; $B$, a layer II non-SC; $C$, a layer III pyramidal cell; $D$, a layer V cell. All four types of cells show activity synchronized to the local field negativity. In addition, all cell types demonstrate the generation of a plateau potential during the production of field activity; however, the depolarization evoked in cells of both layers III $(C)$ and $\mathrm{V}(D)$ show a markedly greater depolarization than that demonstrated in either layer II subtypes.

\section{Layer V Neuron}

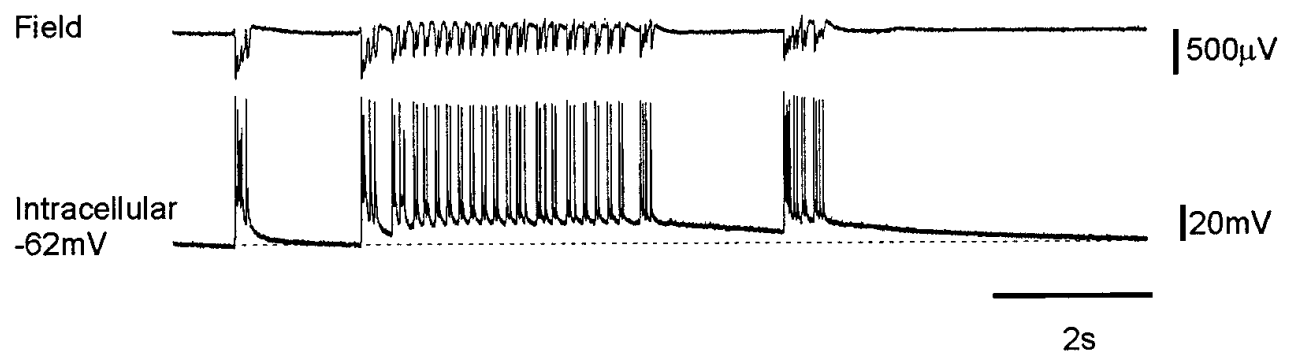

reference electrode was centered in layer II, and a second moving electrode recorded activity at increasing fixed $50 \mu \mathrm{m}$ steps in the mediolateral or laminar axis (Fig. $11 A$ ). Figure $11, B$ and $D$, demonstrates that as the distance from the reference electrode increased, the amplitude of the reference field event decreased and became practically undetectable at a distance of $\sim 200-300$ $\mu \mathrm{m}$. Despite large-amplitude changes at these distances, no measurable latency changes were apparent in the waveform recorded at the moveable electrode. At the same time, as the distance from the reference electrode increased, other field events not detected by the reference electrode appeared in the moving electrode (Fig. $11 B$, traces 4 and 5). Profiles conducted in both the medial and lateral directions with respect to the stationary electrode (Fig. $11 D$ ) demonstrated similar findings. Laminar profile analysis also indicated that the layer II positive events reversed in the upper layer III to become quickly undetectable as the test electrode was advanced further toward layer IV (Fig. 11B).

\section{DISCUSSION}

This report focused on the ability of muscarinic receptor activation with $\mathrm{CCh}$ to trigger rhythmic population activity in the EC slice. CCh, in moderate concentrations (10-30 $\mu \mathrm{M})$, indeed triggered population activity in EC, which had an epileptiform character. Similar to that of the neocortex, epileptiform activity in EC was typically driven by layer V; however, an isolated layer II was also able to generate epileptiform events. Because EC layers II and $\mathrm{V}$ gate the cortical input and output, respectively, of the hippocampal formation (Sorensen and Shipley, 1979; Van Hoesen, 1982; Swanson and Kohler, 1986; Witter et al., 1986; Witter, 1989), our data suggest that they may act as powerful distributors of epileptiform activity throughout the temporal lobe. In addition, we also found that $\mathrm{CCh}$ synchronized firing of inhibitory interneurons by a mechanism not necessarily dependent on principal cell activation (Michelson and Wong, 1994).

The epileptiform activity induced by $\mathrm{CCh}$ in EC showed sim- 


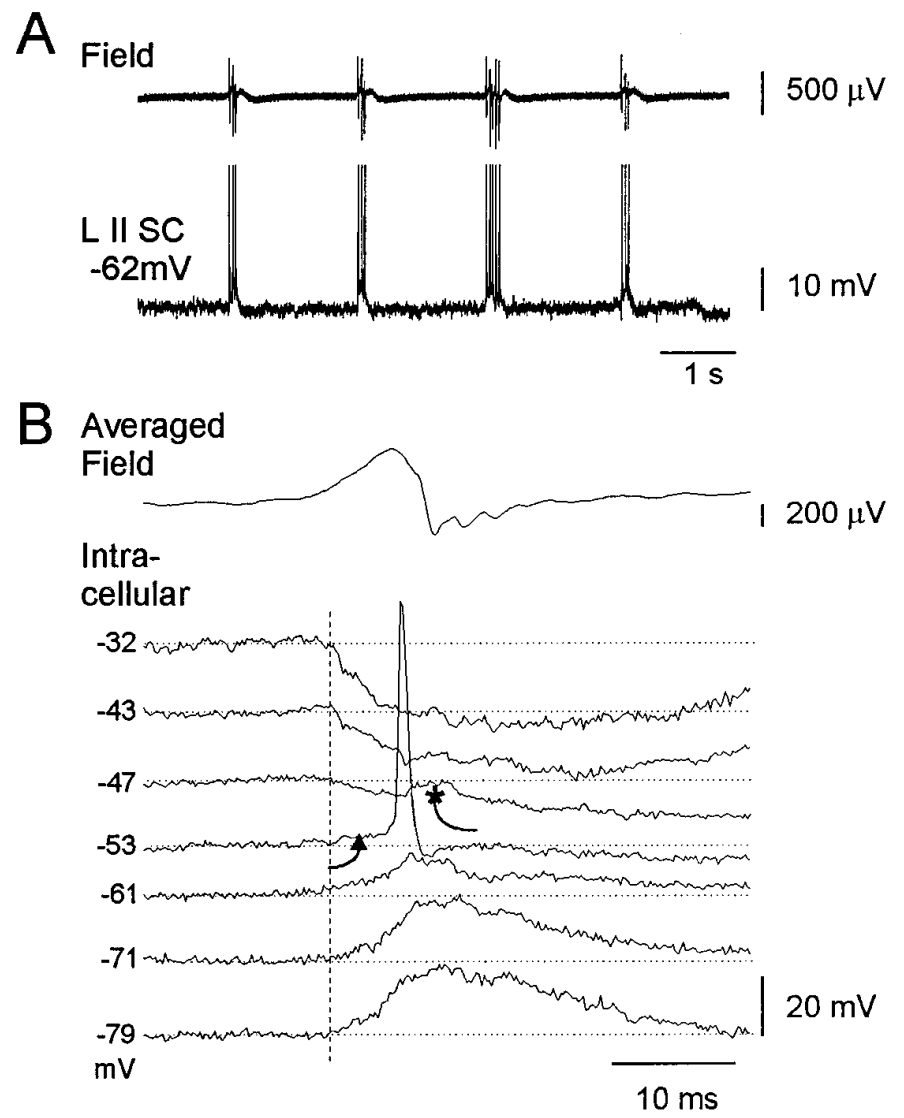

Figure 8. Reversal of synaptic events induced by $\mathrm{CCh}$ in a layer II SC. $A$, A long trace of activity induced by $30 \mu \mathrm{M} C \mathrm{Ch}$. $B$, Alterations in amplitude and direction of potential changes induced by depolarizing and hyperpolarizing current injection. At potentials near and just above the firing threshold of the cell, the intracellular trace appears biphasic, with an initial component reversing at approximately $-50 \mathrm{mV}$ (arrow) and another reversing approximately $5-10 \mathrm{mV}$ more positive (asterisk).

ilarities to that observed in the combined entorhinal-hippocampal slice using several proconvulsive manipulations such as low $\mathrm{Mg}^{2+}$ (Walther et al., 1986), high $\mathrm{K}^{+}$(Bear and Lothman, 1993), $\mathrm{GABA}_{\mathrm{A}}$ receptor block (Jones and Heinemann, 1988), 4-aminopyridine (4-AP) (Avoli et al., 1996), and pilocarpine (Nagao et al., 1996). In all cases, LDEs appeared to be generated by the EC and were maintained exclusively in that region after its surgical isolation.

Recent clinical data have also highlighted the importance of EC in epilepsy. Sclerotic lesions, long thought to be limited to the hippocampus in temporal lobe epilepsy (Babb, 1991; Meenchke and Veith, 1991; Swanson, 1995), have recently been demonstrated to include cortex further lateral in the temporal lobe, including the EC (Gloor, 1991; Levesque et al., 1991; Du et al., 1993). Furthermore, EC stimulation generates field potentials in the hippocampus that resemble spontaneous interictal discharge (Rutecki et al., 1989), and limbic seizures recorded with depth or subdural strip electrodes demonstrate focal seizure generation in EC (Spencer and Spencer, 1994). Moreover, recent surgical evidence has pointed to the role of entorhinal removal in controlling intractable temporal lobe seizures (Goldring et al., 1992, 1993; Fried, 1993; Feindel et al., 1996).

Our laminar field potential profile and CSD analysis clearly indicated that the CCh-induced epileptiform discharges were initiated in layer $\mathrm{V}$ from where they propagated actively toward layers III and II at a speed of $\sim 0.1 \mathrm{~m} / \mathrm{sec}$. In addition, horizontal field potential profiles also demonstrated that layer $\mathrm{V}$ could contain several foci from where epileptiform events propagated horizontally in either the medial or lateral direction, also at a speed of $\sim 0.1 \mathrm{~m} / \mathrm{sec}$ (Miles et al., 1988; Chagnac-Amitai and Connors, 1989a; Traub et al., 1993). It thus appears that once the activity is initiated by a small pool of layer $\mathrm{V}$ neurons, it spreads rapidly throughout the EC. That layer $\mathrm{V}$ neurons are primarily responsible for the generation of $\mathrm{CCh}$-induced epileptiform activity is consistent with previous studies in the neocortical slice (Chagnac-Amitai and Connors, 1989b; Silva et al., 1991; Prince, 1993). A role of EC layer $V$ neurons in the generation of epileptiform activity in the $\mathrm{Mg}^{2+}$-free model has also been suggested recently (Jones and Heinemann, 1988).

A leading role of EC layer $\mathrm{V}$ in the generation of epileptiform events was definitively established by focal $\mathrm{CCh}$ applications and surgical isolation experiments. Focal CCh applications in layer $\mathrm{V}$ always resulted in robust synchronous activity that was actively propagated toward superficial layers. In addition, a surgically isolated layer $\mathrm{V}$ continued to robustly generate epileptiform activity. The spread of epileptiform activity from layer $\mathrm{V}$ to layers III and II is consistent with the known unidirectional organization of the EC layer connections in which each EC layer innervates every layer situated superficially to it (Kohler, 1986b).

Interestingly, our experiments also pointed out that EC layer II, but not layer III, also has the capacity to independently generate hypersynchronous rhythmic population activity. Indeed, focal $\mathrm{CCh}$ applications to layer II frequently resulted in locally generated long trains of rhythmic population activity that did not actively spread to deeper layers, and a surgically isolated layer II was often found to sustain short or long ictiform discharges. Thus, in the EC, both layers $\mathrm{V}$ and II seem to have the adequate neuronal and circuit machinery for the generation of hypersynchronous population activity. In the neocortex, an isolated layer II/III has recently been shown to generate population events at a slow frequency in response to kainic acid application (Flint and Connors, 1996).

EC layer II contains two morphologically and electrophysiologically distinct principal cell types: the SCs and pyramidal-like cells (Alonso and Klink, 1993). The SCs generate rhythmic subthreshold membrane potential oscillations, the manifestation of which is facilitated by muscarinic receptor activation (Klink and Alonso, 1997b). The pyramidal-like cells behave more similarly to regularly spiking neocortical neurons, and muscarinic receptor activation facilitates in them the generation of intrinsic bursting activity (Klink and Alonso, 1997b). Both neuronal types display a profuse net of recurrent axonal collaterals that distribute extensively over layer II (Kohler, 1986b) (R. Klink and A. Alonso, unpublished observations). EC layer II thus appears to contain the appropriate neuronal and circuit mechanisms for the local promotion of oscillatory dynamics, and it is thus not surprising that $\mathrm{CCh}$ triggers synchronized population oscillations locally in layer II.

The inability of EC layer III to independently generate synchronized population oscillations in response to $\mathrm{CCh}$ was particularly evidenced by the inability of focal layer III CCh applications to induce population oscillations, in spite of the fact that focal $\mathrm{CCh}$ applications do cause direct depolarizing responses in these neurons (R. Klink and A. Alonso, unpublished observations). This finding is somewhat consistent with the absence of intrinsic oscillatory neurons in layer III (Dickson et al., 1997) and the more restricted horizontal projections of layer III as com- 


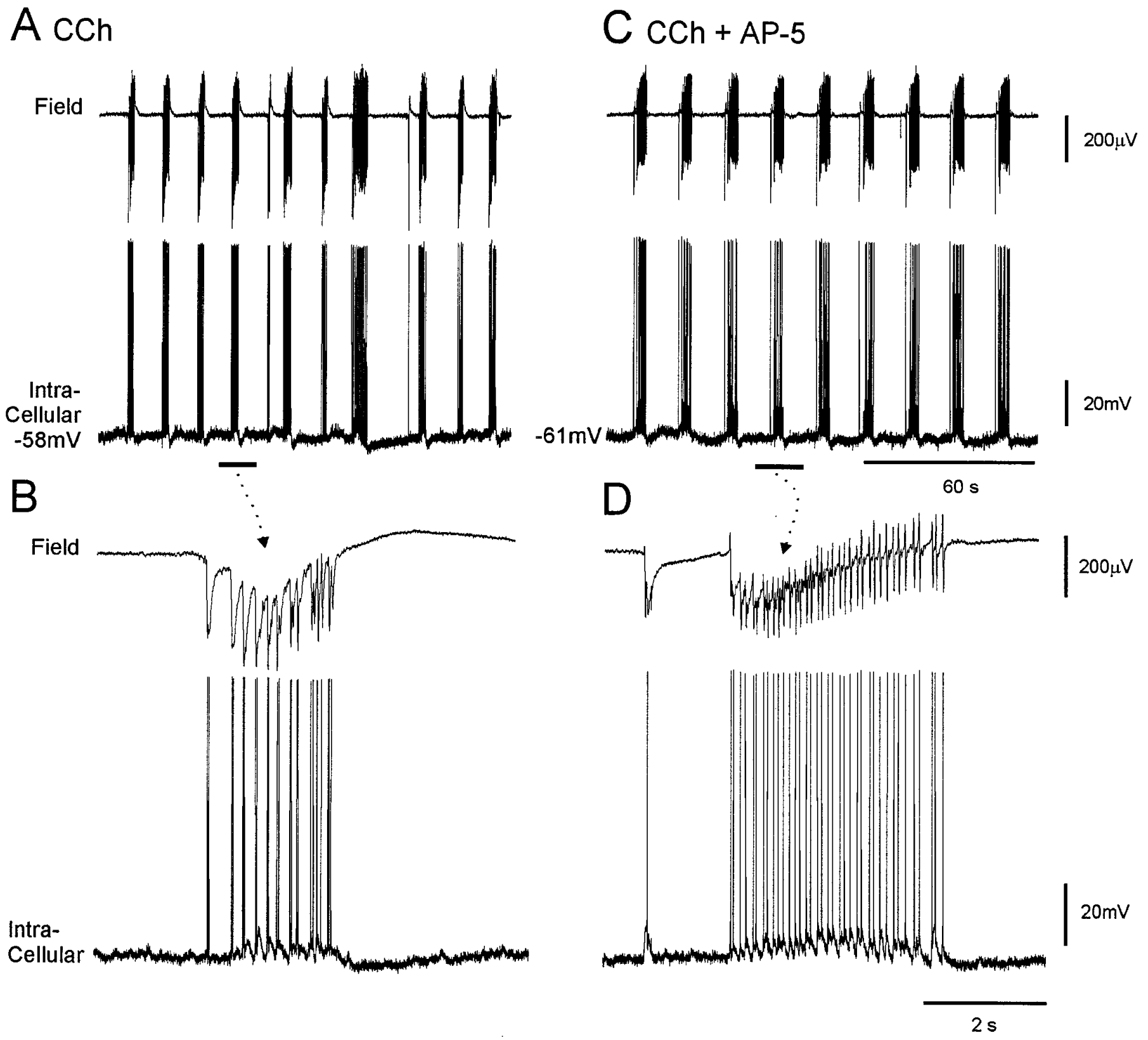

Figure 9. Field events elicited by $\mathrm{CCh}$ are not abolished by pharmacological blockade of NMDA receptors. $A$, Local field and corresponding intracellular activity in a layer II non-SC elicited by $20 \mu \mathrm{M} \mathrm{CCh}$. SDEs are elicited at a frequency of $0.8 \mathrm{~Hz}$ and have an average duration of $2.9 \pm 1.1$ sec. $B$, A single field event from $A$ shown at expanded time scale. Individual field spikes averaged $134 \pm 49$ msec for three events taken from this sample and occurred at a frequency of $5.5 \mathrm{~Hz}$. C, Bath perfusion of AP-5 $(30 \mu \mathrm{M})$ did not abolish the field activity or the paroxysms in the neuron; however, the duration of the field events increased slightly to $4.0 \pm 0.1 \mathrm{sec}$. $D$, An expanded trace from $C$. Individual field spikes averaged $98 \pm 25 \mathrm{msec}$ and occurred at a frequency of $11.3 \mathrm{~Hz}$.

pared with those of layer II (Kohler, 1986b). Our CSD and intracellular recording analysis indicate, however, that during the epileptiform events layer III neurons are subjected to very strong excitatory synaptic bombardment (presumably from layer V neurons) (Scharfman, 1996; Gloveli et al., 1997). It might be that a massive NMDA receptor activation in layer III cells, caused by hyperactivation of layer $\mathrm{V}$ neurons, is at the basis of the robust layer III neuronal degeneration observed in temporal lobe epilepsy (Du et al., 1993, 1995). It is tempting to speculate that during chronic epilepsy the loss of the layer III input onto layer II (Kohler, 1986b) may lead to sprouting of the recurrent collaterals of layer II cells, thereby enhancing feedback excitation and thus the epileptiform tendency of layer II.

Our intracellular analysis demonstrated that principal neurons in all EC layers discharged bursts of action potentials synchronized with the local negative-going field spikes. In all cases, membrane hyperpolarization revealed that these bursts were driven by large-amplitude synaptic events. In layer II neurons, these synaptic events were always fully reversed at approximately $-40 \mathrm{mV}$, and we could always detect an early component that reversed at slightly more hyperpolarized levels. This suggests that the epileptogenic synaptic events are probably the compound 


\section{A CCh+AP-5+CNQX}

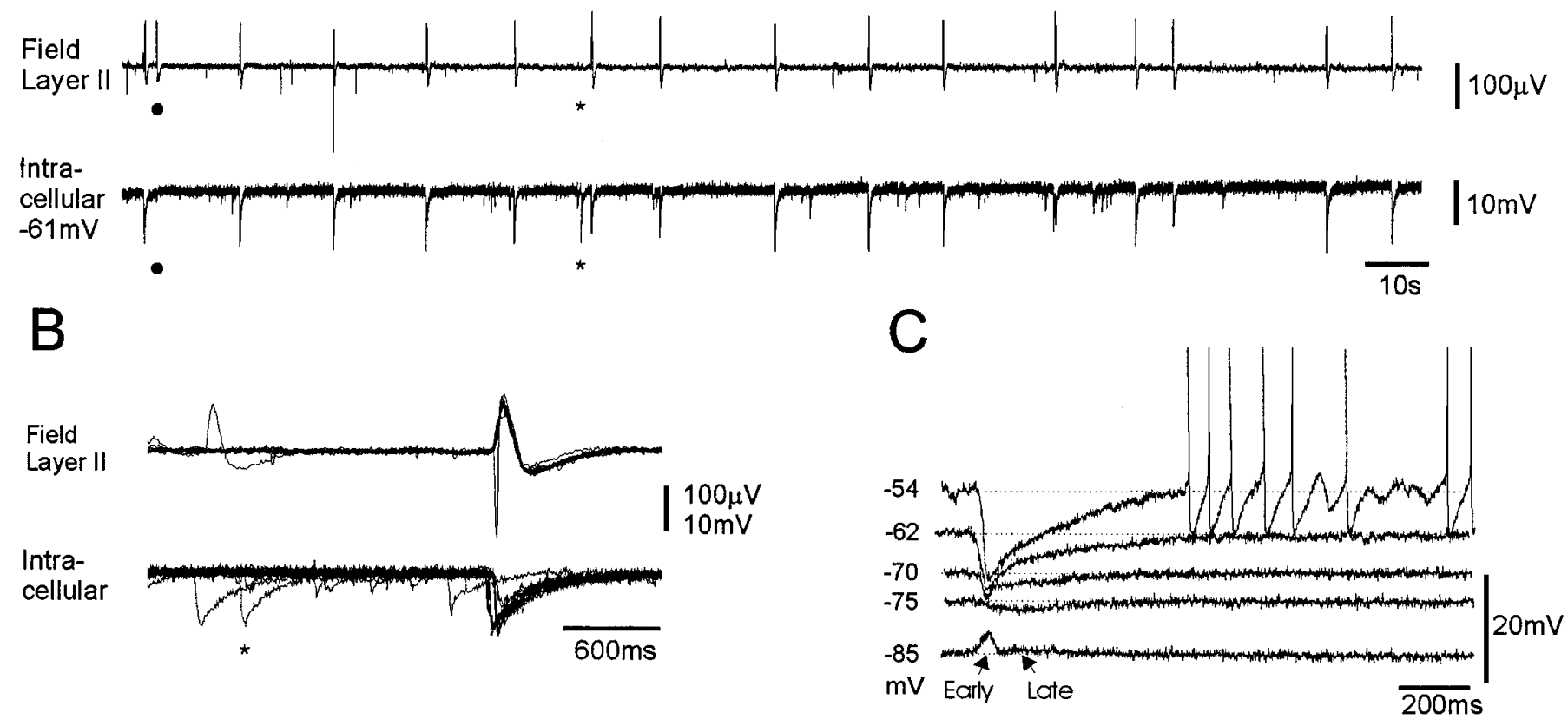

\section{CCh+AP-5+CNQX+PTX}

Field

Layer II

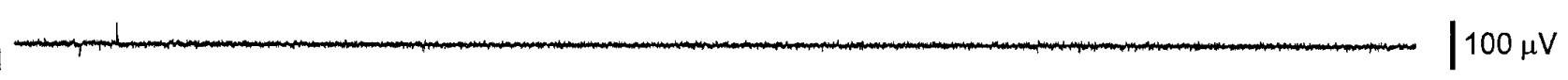

Intra-

cellular

$-62 m \mathrm{~m}$

$10 \mathrm{mV}$

Figure 10. During CCh superfusion, blockade of EAA neurotransmission reveals synchronized firing of inhibitory interneurons. $A$, During perfusion with $10 \mu \mathrm{M}$ CNQX and $30 \mu \mathrm{M}$ AP-5, excitatory paroxysms in a layer II stellate were abolished; however, small-amplitude positive-directed field events (top trace) persist that correspond to giant IPSPs in the intracellular recording (bottom trace). $B$, Superimposition of field events in $A$ shown at a faster sweep speed demonstrates a relative degree of discordance between the field and intracellular recordings. Although the field events appear roughly similar, there is not a perfect synchrony of the corresponding IPSPs, some of which occur at a slightly different phase of the field event. In addition, field events could be unaccompanied by a gIPSP $(\bullet)$, and conversely gIPSP could be unaccompanied by a field event $(*)$. $C$, Membrane hyperpolarization reveals that the fast component of the gIPSP reverses at approximately $-75 \mathrm{mV}$, whereas a slower component reverses at more negative potentials. $D$, Blockade of fast GABAergic neurotransmission with picrotoxin $(P T X)(100 \mu \mathrm{M})$ abolished both the field and the intracellular events.

action of both glutamatergic-mediated EPSPs and GABAergicmediated IPSPs. Similar data have been reported during perfusion of hippocampal slices with 4-AP (Rutecki et al., 1987), and simultaneous firing of interneurons and principal cells has been described in the high potassium model of epilepsy in the hippocampus in vitro (McBain, 1994), as well as during paroxysmal events in vivo (Steriade et al., 1994; Bragin et al., 1995, 1997; Steriade and Contreras, 1995). Moreover, in epileptic human mesial temporal lobe tissue, the observation of synchronized synaptic potentials with similar reversal properties as observed in the present study has also led to the suggestion of concomitant activation of inhibitory and excitatory synaptic input (Schwartzkroin and Knowles, 1984).

The maintenance of the ictiform activity induced by $\mathrm{CCh}$ appeared selectively dependent on fast EAA neurotransmission, because it was only modulated by NMDA receptor antagonism but blocked by AMPA-receptor antagonism. This pharmacological profile is similar to that reported for $\mathrm{CCh}$ - induced rhythmic population oscillations in the hippocampus (MacVicar and Tse, 1989). In the EC, however, smallamplitude, positive-going field events persisted in layer II during combined block of both AMPA and NMDA receptors. These events occurred periodically and were correlated with gIPSPs in layer II principal cells and abolished by $\mathrm{GABA}_{\mathrm{A}}$ receptor antagonism. Recurrent gIPSPs in principal cells during EAA neurotransmission block have also been observed in the neocortical and hippocampal slice in the presence of 4-AP (Aram et al., 1991; Perrault and Avoli, 1992; Michelson and Wong, 1994). Also, recently, 4-AP application to EC slices has been shown to induce long-lasting depolarizations in principal neurons that persisted during EAA neurotransmission block and were markedly depressed by $\mathrm{GABA}_{\mathrm{A}}$ receptor antagonism (Lopantsev and Avoli, 1996). Furthermore, synchronized synaptic potentials observed in epileptic human mesial temporal lobe tissue were also found to be dependent on fast GABAergic neurotransmission (Schwartzkroin and Haglund, 1986). 
A

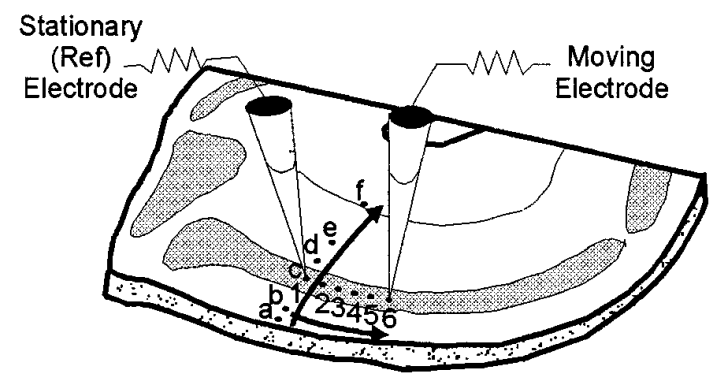

C Laminar Profile

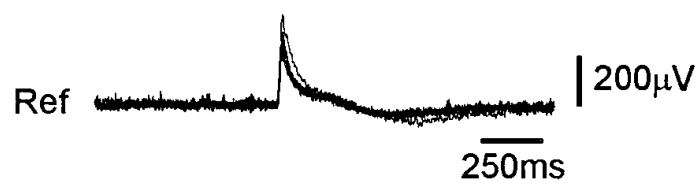

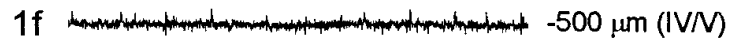

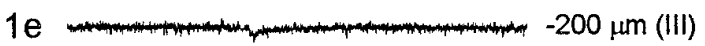

$1 \mathrm{~d}$

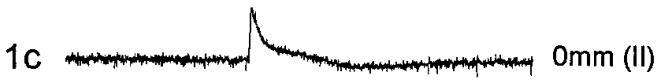

$1 \mathrm{~b}+150 \mu \mathrm{m}$ (I)

$1 \mathrm{a}+250 \mu \mathrm{m}$ (I/Pia)
B Horizontal Profile

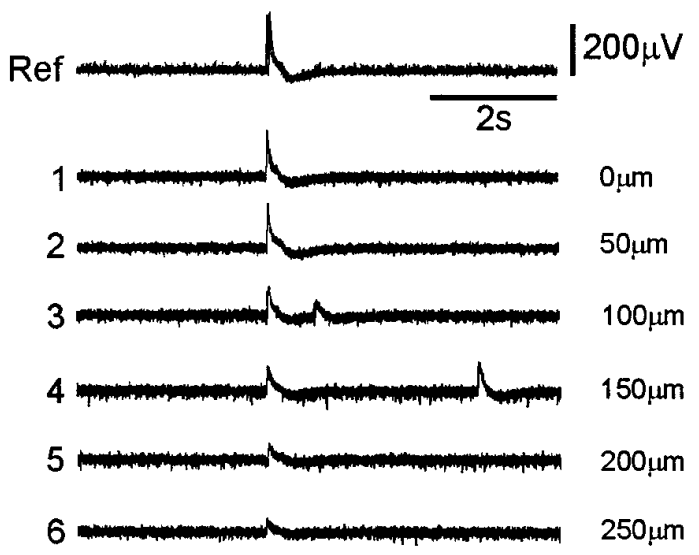

D Horizontal Profile 2

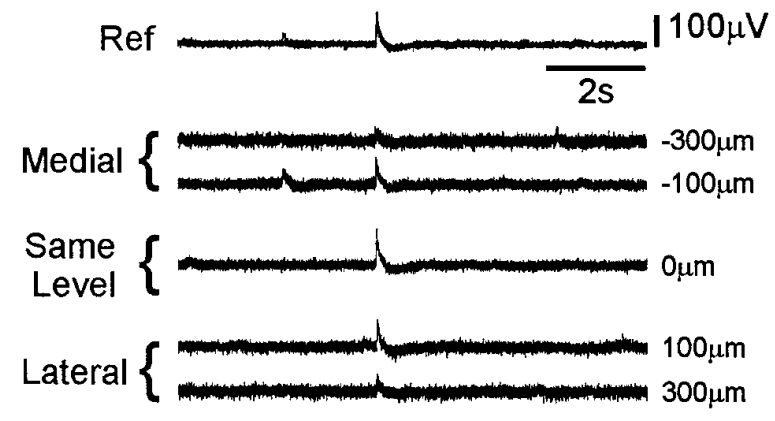

Figure 11. Horizontal and laminar profiles of GABAergic field potentials in layer II. $A$, Experimental setup. Small-amplitude positive field events were elicited by $20 \mu \mathrm{M} \mathrm{CCh}$ in the presence of $10 \mu \mathrm{M}$ CNQX and $30 \mu \mathrm{M} \mathrm{AP-5.} \mathrm{A} \mathrm{stationary} \mathrm{electrode} \mathrm{was} \mathrm{centered} \mathrm{in} \mathrm{layer} \mathrm{II,} \mathrm{and} \mathrm{a} \mathrm{moving} \mathrm{electrode} \mathrm{was}$ used to construct both a horizontal and a laminar profile. $B$, Results of the horizontal profile (shown in $A$ as sites numbered 1-6). The amplitude of positive field events appears to decay monotonically as the roving electrode is moved further lateral. In addition, independent field events were apparent at lateral distances as close as $100 \mu \mathrm{m}$, which showed little to no correspondence at the reference site (traces 3 and 4 ). $C$, Results of the laminar profile conducted in the same slice (shown in $A$ as sites lettered $a-f$ ). The amplitude of the signal rapidly decays as the electrode is displaced from layer II; however, a measurable reversal appears in upper layer III (trace 1e). D, Results of a horizontal profile in another slice in which the trajectory of the roving electrode passed sites both medial and lateral to the reference electrode. Similar to the results shown in $B$, the waveform decays monotonically at distant sites in both the medial and lateral directions.

The mechanism of 4-AP-induced synchronization of inhibitory neurons in the hippocampus has been studied in detail by Michelson and Wong (1994). These authors reported that in the presence of 4-AP and during blockade of EAA neurotransmission, gIPSPs occur rhythmically in hippocampal principal cells. These gIPSPs were invariably triphasic in appearance, and PTX blocked the fast initial event $\left(\mathrm{GABA}_{\mathrm{A}}\right.$ mediated) and left in isolation a slower monophasic event $\left(\mathrm{GABA}_{\mathrm{B}}\right.$ mediated). These authors also concluded that hippocampal GABAergic interneurons may become synchronized via (1) recurrent interneuron collaterals and the depolarizing action of synaptically activated $\mathrm{GABA}_{\mathrm{A}}$ receptors and (2) electrotonic coupling. Similar mechanisms may also operate in EC (Buhl and Jones, 1993; Wouterlood et al., 1995). Even though the gIPSPs in EC layer II neurons were not triphasic in appearance, they did demonstrate a fast rise time ( $\sim 43 \mathrm{msec}$ ) compatible with $\mathrm{GABA}_{\mathrm{A}}$ receptor activation (Michelson and Wong, 1991) and a slow decay compatible with $\mathrm{GABA}_{\mathrm{B}}$ receptor activation. In addition, the early phase reversed at approximately $-75 \mathrm{mV}$, whereas the slow late phase reversed $\sim 10$ $\mathrm{mV}$ more negative.

The fact that the gIPSPs in layer II neurons were correlated with the locally generated positive field events suggests that these events result from inhibitory synaptic currents in projection cells. Because there was not always a perfect synchrony between the field events and the gIPSPs (Fig. 10), and because field events recorded at sites separated by distances greater than $\sim 200 \mu \mathrm{m}$ tended to be uncorrelated (Fig. 11), this suggests that these events arise from the synchronous activation of discrete, localized pools of interneurons that innervate discrete, localized pools of principal cells (Freund and Buzsaki, 1996). Thus, inhibitory networks may play a fundamental role in the organization of population dynamics (Llinas et al., 1991; Cobb et al., 1995; Jefferys et al., 1996; Wang and Buzsaki, 1996) and functional domains within the EC.

\section{REFERENCES}

Alonso A, García-Austt E (1987a) Neuronal sources of theta rhythm in the entorhinal cortex of the rat. II. Phase relations between unit discharges and theta field potentials. Exp Brain Res 67:502-509.

Alonso A, García-Austt E (1987b) Neuronal sources of theta rhythm in the entorhinal cortex. I. Laminar distribution of theta field potentials. Exp Brain Res 67:493-501.

Alonso A, Klink R (1993) Differential electroresponsiveness of stellate and pyramidal-like cells of medial entorhinal cortex layer II. J Neurophysiol 70:128-143. 
Alonso A, Köhler C (1984) A study of the reciprocal connections between the septum and the entorhinal area using anterograde and retrograde axonal transport methods in the rat brain. J Comp Neurol 225:327-343

Amaral DG, Insausti R, Cowan WM (1983) Evidence for a direct projection from the superior temporal gyrus to the entorhinal cortex in the monkey. Brain Res 275:263-277.

Aram JA, Michelson HB, Wong RKS (1991) Synchronized GABAergic IPSPs recorded in the neocortex after blockade of synaptic transmission mediated by excitatory amino acids. J Neurophysiol 65:1034-1041.

Avoli M, Barbarosie M, Lucke A, Nagao T, Lopantsev V, Kohling R (1996) Synchronous GABA-mediated potentials and epileptiform discharges in the rat limbic system in vitro. J Neurosci 16:3912-3924.

Babb TL (1991) Research on the anatomy and pathology of epileptic tissue. In: Epilepsy surgery (Luders H, ed), pp 719-727. New York: Raven.

Bear J, Lothman EW (1993) An in vitro study of focal epileptogenesis in combined hippocampal-parahippocampal slices. Epilepsy Res 14:183-193.

Beldhuis HJA, De Ruiter AJH, Maes FW, Suzuli T, Bohus B (1993) Long-term increase in protein kinase $\mathrm{C}-\gamma$ and muscarinic acetylcholine receptor expression in the cerebral cortex of amygdala-kindled rats: a quantitative immunocytochemical study. Neuroscience 55:965-973.

Bianchi R, Wong RKS (1994) Carbachol-induced synchronized rhythmic bursts in CA3 neurons of guinea-pig hippocampus in vitro. J Neurophysiol 72:131-138.

Bragin A, Jando G, Nadasdy Z, van Landeghem M, Buzsaki G (1995) Dentate EEG spikes and associated interneuronal population bursts in the hippocampal hilar region of the rat. J Neurophysiol 73:1691-1705.

Bragin A, Csicsvari J, Penttonen M, Buzsaki G (1997) Epileptic afterdischarge in the hippocampal-entorhinal system: current source density and unit studies. Neuroscience 76:1187-1203.

Buhl EH, Jones RSG (1993) Basket-like interneurons in layer II of the entorhinal cortex exhibit a powerful NMDA-mediated synaptic inhibition. Neurosci Lett 149:35-39.

Cain DP (1989) Excitatory neurotransmitters in kindling: excitatory amino acid, cholinergic, and opiate mechanisms. Neurosci Biobehav Rev 13:269-276.

Chagnac-Amitai Y, Connors BW (1989a) Horizontal spread of synchronized activity in neocortex and its control by GABA-mediated inhibition. J Neurophysiol 61:747-757.

Chagnac-Amitai Y, Connors BW (1989b) Synchronized excitation and inhibition driven by intrinsically bursting neurons in neocortex. J Neurophysiol 62:1149-1162.

Cobb S, Buhl E, Halasy K, Paulsen O, Somogyi P (1995) Synchronization of neuronal activity in hippocampus by individual GABAergic interneurons. Nature 378:75-78.

Coutinho-Netto J, Boyar M, Bradford HF, Birdsall NJM, Hulme EC (1981) Acetylcholine release and muscarinic receptors in cortical synaptosomes from epileptic rats. Exp Neurol 74:837-846.

Dasheiff RM, McNarmara JO (1982) Electrolytic entorhinal lesions cause seizures. Brain Res 231:444-450.

Deacon TW, Eichenbaum H, Rosenberg P, Eckmann KW (1983) Afferent connections of the perirhinal cortex in the rat. J Comp Neurol 220:168-190.

Deutch C, Spencer S, Robbins R, Cicchetti D, Spencer D (1991) Interictal spikes and hippocampal somatostatin levels in temporal lobe epilepsy. Epilepsia 32:174-178.

Dickson CT (1994) The extrinsic modulation of entorhinal cortex theta: field and unit activity studies. PhD thesis, University of Calgary.

Dickson CT, Alonso A (1995a) The entorhinal cortex contains two intrinsic pacemakers of epileptiform activity: an in vitro study. Epilepsia 36: [Suppl]4:87.

Dickson CT, Alonso A (1995b) Layers II and IV of the entorhinal cortex are robust intrinsic generators of epileptiform activity: an in vitro study. Soc Neurosci Abstr 21:777.

Dickson CT, Kirk IJ, Oddie SD, Bland BH (1995) Classification of theta-related cells in the entorhinal cortex: cell discharges are controlled by the ascending brainstem synchronizing pathway in parallel with hippocampal theta-related cells. Hippocampus 5:306-319.

Dickson CT, Mena AR, Alonso A (1997) Electroresponsiveness of medial entorhinal cortex layer III neurons in vitro. Neuroscience, in press.

Dolorfo CL, Amaral DG (1997) The entorhinal cortex of the rat: organization of intrinsic connections. J Comp Neurol, in press.

Du F, Whetsell WO, Abou-Khalil B, Blumenkopf B, Lothman EW, Schwarcz R (1993) Preferential neuronal loss in layer III of the ento- rhinal cortex in patients with temporal lobe epilepsy. Epilepsy Res 16:223-233.

Du F, Tore E, Kohler C, Lothman EW, Schwarcz R (1995) Preferential neuronal loss in layer III of the medial entorhinal cortex in rat models of temporal lobe epilepsy. J Neurosci 15:8301-8313.

Engel JJ (1987) Surgical treatment of the epilepsies. New York: Raven.

Feindel W, Leonard G, Caramanos Z, Li M, Harrison J, Kuchela A (1996) Role of the amygdala and entorhinal cortex in the surgery of temporal lobe seizures. Can J Neurol Sci 26:G07.

Flint AC, Connors BW (1996) Two types of network oscillations in neocortex mediated by distinct glutamate receptor subtypes and neuronal populations. J Neurophysiol 75:951-956.

Freund T, Buzsaki G (1996) Interneurons of the hippocampus. Hippocampus 6:347-470.

Fried I (1993) Anatomic temporal lobe resections for temporal lobe epilepsy. Epilepsy Surg 4:233-242.

Gaykema RPA, Luiten PGM, Nyakas C, Traber J (1990) Cortical projection patterns of the medial septum-diagonal band complex. J Comp Neurol 293:103-124

Gloor P (1991) Mesial temporal sclerosis: historical background and an overview from a modern perspective. In: Epilepsy surgery (Luders $\mathrm{H}$, ed), pp 689-703. New York: Raven.

Gloveli T, Schmitz D, Empson RM, Dugladze T, Heinemann U (1997) Morphological and electrophysiological characterization of layer III cells of the medial entorhinal cortex of the rat. Neuroscience 77:629-648.

Goldring S, Edwards I, Harding GW, Bernardo KL (1992) Results of anterior temporal lobectomy that spares the amygdala in patients with complex partial seizures. J Neurosurg 77:185-193.

Goldring S, Edwards I, Harding GW, Bernardo KL (1993) Temporal lobectomy that spares the amygdala for temporal lobe epilepsy. Epilepsy Surg 4:263-272.

Huerta PT, Lisman JE (1993) Heightened synaptic plasticity of hippocampal CA1 neurones during a cholinergically induced rhythmic state. Nature 19:723-725.

Insausti R, Amaral DG, Cowan WM (1987) The entorhinal cortex of the monkey: II. Cortical afferents. J Comp Neurol 264:356-395.

Insausti R, Herrero MT, Witter MP (1997) Entorhinal cortex of the rat: cytoarchitectonic subdivisions and the origin and distribution of cortical efferents. Hippocampus 7:146-183.

Jefferys J, Traub R, Whittington M (1996) Neuronal networks for induced "40Hz" rhythms. Trends Neurosci 19:202-208.

Jones EG, Powell TPS (1970) An anatomical study of converging sensory pathways within the cerebral cortex of the monkey. Brain 93:793-820.

Jones RSG, Heinemann V (1988) Synaptic and intrinsic responses of medial entorhinal cortical cells in normal and magnesium-free medium "in vitro". J Neurophysiol 59:1476-1496.

Jones RSG, Heinemann UFH, Lambert JDC (1992) The entorhinal cortex and generation of seizure activity: studies of normal synaptic transmission and epileptogenesis. In: Neurotransmitters in epilepsy (Epilepsy Res Suppl 8) (Avanzini G, Engel JJ, Fariello R, Heinemann U, eds), pp 173-180. Amsterdam: Elsevier.

Kish SJ, Olivier A, Dubeau F, Robitaille Y, Sherwin AL (1988) Increased activity of choline acetyltransferase and acetylcholinesterase in actively epileptic human cerebral cortex. Epilepsy Res 2:227-231.

Klink R, Alonso A (1997a) Ionic mechanisms of muscarinic depolarization in entorhinal cortex layer II neurons. J Neurophysiol 77:1829-1843.

Klink R, Alonso A (1997b) Muscarinic modulation of the oscillatory and repetitive firing properties of entorhinal cortex layer II neurons. J Neurophysiol 77:1813-1828.

Klink R, Dickson CT, Alonso A (1995) Intracellular correlates of synchronous excitatory and inhibitory activity induced by carbachol in entorhinal cortex layer II. Soc Neurosci Abstr 21:987.

Kohler C (1986a) Chemical architecture of the entorhinal cortex. In: Excitatory amino acids and epilepsy (Ben-Ari Y, Schwarcz R, eds), pp 83-98. New York: Plenum.

Kohler C (1986b) Intrinsic connections of the retrohippocampal region in the rat brain. II. The medial entorhinal area. J Comp Neurol 246:149-169.

Konopacki J, MacIver MB, Roth SH, Bland BH (1987) Carbacholinduced EEG "theta" activity in hippocampal brain slices. Brain Res 405:196-198.

Levesque MF, Nakasato N, Vinters HV, Babb TL (1991) Surgical treat- 
ment of limbic epilepsy associated with extrahippocampal lesions: the problem of dual pathology. J Neurosurg 75:364-370.

Lewis PR, Shute CCD (1967) The cholinergic limbic system: projections to hippocampal formation, medial cortex, nuclei of the ascending cholinergic reticular system, and the subfornical organ and supra-optic crest. Brain 90:521-540.

Llinas RR, Grace AA, Yarom Y (1991) In vitro neurons in mammalian cortical layer 4 exhibit intrinsic oscillatory activity in the $10-$ to $50-\mathrm{Hz}$ frequency range. Proc Natl Acad Sci USA 88:897-901.

Lopantsev V, Avoli M (1996) Reverberation of chloride-dependent synaptic potentials in the rat entorhinal cortex in vitro. Neurosci Lett 210:5-8.

Lopes da Silva FH, Witter MP, Boeijinga PH, Lohman HM (1990) Anatomic organization and physiology of the limbic cortex. Physiol Rev 76:453-511.

Lothman EW, Bertram EHI, Stringer JL (1991) Functional anatomy of hippocampal seizures. Prog Neurobiol 37:1-82.

Lysakowski A, Wainer BH, Bruce G, Hersh LB (1989) An atlas of the regional and laminar distribution of choline acetyltransferase immunoreactivity in rat cerebral cortex. Neuroscience 28:291-336.

MacVicar BA, Tse FWY (1989) Local neuronal circuitry underlying cholinergic rhythmical slow activity in CA3 area of rat hippocampal slices. J Physiol (Lond) 417:197-212.

McBain CJ (1994) Hippocampal inhibitory neuron activity in the elevated potassium model of epilepsy. J Neurophysiol 72:2853-2863.

Meenchke HJ, Veith G (1991) Hippocampal sclerosis in epilepsy. In: Epilepsy surgery (Luders H, ed), pp 705-715. New York: Raven.

Mellgren SI, Srebro B (1973) Changes in acetylcholinesterase and distribution of degenerating fibres in the hippocampal region after septal lesions in the rat. Brain Res 52:19-36.

Michelson HB, Wong RKS (1991) Excitatory synaptic responses mediated by $\mathrm{GABA}_{\mathrm{A}}$ receptors in the hippocampus. Science 1420-1423.

Michelson HB, Wong RKS (1994) Synchronization of inhibitory neurones in the guinea-pig hippocampus in vitro. J Physiol (Lond) 477:35-45.

Miles R, Traub RD, Wong RKS (1988) Spread of synchronous firing in longitudinal slices form the CA3 region of the hippocampus. J Neurophysiol 60:1481-1496.

Milner TA, Loy R, Amaral DG (1983) An anatomical study of the development of the septo-hippocampal projection in the rat. Dev Brain Res 8:343-371.

Mitchell SJ, Ranck JBJ (1980) Generation of theta rhythm in medial entorhinal cortex of freely moving rats. Brain Res 189:49-66.

Mitzdorf U (1985) Current source-density method and application in cat cerebral cortex: investigation of evoked potentials and EEG phenomena. Physiol Rev 65:37-100.

Nagao T, Alonso A, Avoli M (1996) Epileptiform activity induced by pilocarpine in the rat hippocampal-entorhinal slice preparation. Neuroscience 72:399-408.

Paré D, de Curtis M, Llinás R (1992) Role of the hippocampalentorhinal loop in temporal lobe epilepsy: extra- and intracellular study in the isolated guinea pig brain in vitro. J Neurosci 12:1867-1881.

Perrault P, Avoli M (1992) 4-Aminopyridine-induced activity in hilar neurons in the guinea pig hippocampal slice. J Neurosci 12:104-115.

Pope A, Morris AA, Jasper H, Elliot KAC, Penfield W (1947) Histochemical and action potential studies on epileptogenic areas of cerebra cortex in man and the monkey. Res Publ Assoc Res Nerv Ment Dis 26:218-231.

Prince DA (1993) Basic mechanisms of focal epileptogenesis. In: Epileptogenic and excitotoxic mechanisms (Avanzini G, Fariello R, Heinemann U, Mutani R, eds), pp 17-27. London: Libbey.

Reep RL, Corwin JV, Hashimoto A, Watson RT (1987) Efferent connections of the rostral portion of medial agranular cortex in rats. Brain Res Bull 19:203-221.

Room P, Groenewegen HJ (1986) The connections of the parahippocampal cortex in the cat. I. Cortical afferents. J Comp Neurol 251:415-450.

Rutecki PA, Lebeda FJ, Johnston, D (1987) 4-Aminopyridine produces epileptiform activity in hippocampus and enhances synaptic excitation and inhibition. J Neurophysiol 57:1911-1924.

Rutecki PA, Grossman RG, Armstrong D, Irish-Loewen S (1989) Electrophysiological connections between the hippocampus and entorhinal cortex in patients with complex partial seizures. J Neurosurg 70:667-675.

Scharfman HE (1996) Hyperexcitability of entorhinal cortex and hippocampus after application of aminooxyacetic acid (AOAA) to layer III of the rat entorhinal cortex in vitro. J Neurophysiol 76:2986-3001.
Schwartzkroin PA (1994) Role of the hippocampus in epilepsy. Hippocampus 4:239-242.

Schwartzkroin PA, Haglund MM (1986) Spontaneous rhythmic synchronous activity in epileptic human and normal monkey temporal lobe. Epilepsia 27:523-533.

Schwartzkroin PA, Knowles WD (1984) Intracellular study of human epileptic cortex: in vitro maintenance of epileptiform activity? Science 223:709-712.

Silva LR, Amital Y, Connors BW (1991) Intrinsic oscillations of neocortex generated by layer 5 pyramidal neurons. Science 251:432-434.

Sorensen KE, Shipley MT (1979) Projections from the subiculum to the deep layers of the ipsilateral presubicular and entorhinal cortices in the guinea pig. J Comp Neurol 188:313-334.

Spencer SS, Spencer DD (1994) Entorhinal-hippocampal interactions in medial temporal lobe epilepsy. Epilepsia 35:721-727.

Steriade M, Contreras D (1995) Relations between cortical and thalamic cellular events during transition from sleep patterns to paroxysmal activity. J Neurosci 15:623-642.

Steriade M, Contreras D, Amzica F (1994) Synchronized sleep oscillations and their paroxysmal developments. Trends Neurosci 17:199-208.

Steward O, Scoville SA (1976) The cells of origin of entorhinal afferents to the hippocampus and fascia dentata of the rat. J Comp Neurol 169:347-370.

Stringer JL, Lothman EW (1992) Reverberatory seizure discharges in hippocampal-parahippocampal circuits. Exp Neurol 116:198-203.

Swanson LW, Cowan WM (1977) An autoradiographic study of the organization of the efferent connections of the hippocampal formation in the rat. J Comp Neurol 172:49-84.

Swanson LW, Kohler C (1986) Anatomical evidence for direct projections from the entorhinal area to the entire cortical mantle in the rat. J Neurosci 6:3010-3023.

Swanson TH (1995) The pathophysiology of human mesial temporal lobe epilepsy. J Clin Neurophysiol 12:2-22.

Tower DB, Elliot DW (1952) Activity of acetylcholine system in human epileptogenic focus. J Appl Physiol 4:669-676.

Tower DB, McEarchern D (1949) Acetylcholine and cholinesterase activity in cerebrospinal fluid of patients with epilepsy. Can J Res E27:120-131.

Traub RD, Miles R, Buzsaki G (1992) Computer simulation of carbachol-driven rhythmic population oscillations in the CA3 region of the in vitro rat hippocampus. J Physiol (Lond) 451:653-672.

Traub RD, Jefferys JGR, Miles R (1993) Analysis of the propagation of disinhibition-induced after-discharges along the guinea-pig hippocampal slice in vitro. J Physiol (Lond) 472:267-287.

Turski L, Ikonomidou C, Turski WA, Bortolotto ZA, Cavalheiro EA (1989) Review: cholinergic mechanisms and epileptogenesis. The seizures induced by pilocarpine: a novel experimental model of intractable epilepsy. Synapse 3:154-171.

Van Hoesen GW (1982) The parahippocampal gyrus: new observations regarding its cortical connections in the monkey. Trends Neurosci 5:345-350.

Van Hoesen GW, Pandya DN (1975) Some connections of the entorhinal (area 28) and perirhinal (area 35) cortices of the rhesus monkey. I. Temporal lobe afferents. Brain Res 95:1-24.

Walther H, Lambert JDC, Jones RSG, Heinemann U, Hamon B (1986) Epileptiform activity in combined slices of the hippocampus, subiculum and entorhinal cortex during perfusion with low magnesium medium. Neurosci Lett 69:165-161.

Wang X-J, Buzsaki G (1996) Gamma oscillation by synaptic inhibition in a hippocampal interneuronal network model. J Neurosci 16:6402-6413.

Wilson WA, Swartzwelder HS, Anderson WW, Lewis DV (1988) Seizure activity in vitro: a dual focus model. Epilepsy Res 2:289-293.

Witter MP (1989) Connectivity of the rat hippocampus. In: The hippocampus-new Vistas (Chan-Palay V, Kohler C, eds), pp 53-69. New York: Alan Liss Inc.

Witter MP, Room P, Groenewegen HJ, Lohman AHM (1986) Connections of the parahippocampal cortex in the cat. V. Intrinsic connections; comments on input/output connections with the hippocampus. J Comp Neurol 252:78-94.

Witter MP, Groenewegen HJ, Lopes da Silva FH, Lohman AHM (1989) Functional organization of the extrinsic and intrinsic circuitry of the parahippocampal region. Prog Neurobiol 33:161-253.

Wouterlood PG, Härtig W, Brückner G, Witter MP (1995) Parvalbuminimmunoreactive neurons in the entorhinal cortex of the rat: localization, morphology, connectivity and ultrastructure. J Neurocytol 24:135-153. 